\title{
Design Oriented Approach to Predict Shear Strength of Reinforced Concrete Beams
}

\author{
Hadi Baghi ${ }^{1}$, Joaquim A. O. Barros ${ }^{2}$
}

\footnotetext{
${ }^{1}$ Post-doc, Civil Engineering and Construction Engineering Technology, Louisiana Tech University, Ruston, U.S., 71272-0046, e-mail: hadibaghi@gmail.com (corresponding author).

${ }^{2}$ Full Professor, ISISE, Department of Civil Engineering, University of Minho, Guimarães, Portugal, e-mail: barros@civil.uminho.pt.
}

\begin{abstract}
There are different approaches to predict the shear strength of reinforced concrete (RC) beams, but their predictive performance is still relatively low due to several and complex resisting mechanisms involved in shear. In addition, most of design approaches ignore the influence of the flange of $\mathrm{T}$ cross section beams on the ultimate shear capacity. This paper aims to present a design oriented approach to predict the load carrying capacity of RC beams failing in shear. This approach is based on the simplified modified compression field theory (SMCFT). A sensitivity analysis is carried out to assess the importance of the input parameters that mostly affect the shear strength of RC members. Taking into account the results of the sensitivity analysis, two simple equations are proposed for obtaining the: i) tensile stress factor in the cracked concrete $(\beta)$; ii) inclination of the diagonal compressive stress in the web of the section $(\theta)$. The obtained equations eliminate the iterative process required by the SMCFT, and provide a straightforward design methodology to find $\beta$ and $\theta$ with suitable accuracy for design purposes. In addition, a coefficient is presented to take into account the effect of the flange on the shear capacity of $\mathrm{T}$ shape cross section beams. To appraise the predictive performance of the new approach, a data base composed of $349 \mathrm{RC}$ beams is set according to available shear tests of RC beams in literature. This data base includes beams of different size, concrete compressive strength, and longitudinal and transverse steel reinforcement ratios. By evaluating the ratio between the experimental results and the analytical predictions, an average value of 1.24 with a coefficient of variation of $20.9 \%$ is obtained, which indicate the developed model has suitable accuracy to predict the shear strength of RC beams.
\end{abstract}

Keywords: Reinforced concrete beams; Shear strength; Simplified Modified Compression Field Theory; Sensitivity Analysis; Monte Carlo simulation; T cross section beams. 


\section{Introduction}

There are different methods to predict the shear strength of reinforced concrete (RC) beams, but their accuracy is still relatively low due to several and complex resisting mechanisms involved such as: concrete in the compression zone, aggregate interlock, dowel effect of longitudinal reinforcement, and contribution of stirrups if present [1, 2]. Beam's cross section dimensions and axial load, if existing, also influence the shear capacity of RC beams. The ACI Building

Code [3] suggests that the nominal shear strength $V_{n}$ of a $\mathrm{RC}$ beam is the sum of the contribution provided by concrete $\left(V_{c}\right)$ :

$$
V_{c}=0.17 \sqrt{f_{c}^{\prime}} b_{w} d
$$

with the contribution of web reinforcement $\left(V_{s}\right)$ :

$$
V_{s}=\frac{A_{s t} f_{s t, y}}{s} d
$$

In equation (1) $f_{c}^{\prime}$ is the concrete compressive strength, while $b_{w}$ and $d$ are the width and effective depth of the beam's cross section, respectively. In equation (2) $A_{s t}$ and $f_{s t, y}$ are the cross sectional area and the yield stress of steel stirrups, and $s$ is the horizontal distance between steel stirrups. The $V_{s}$ is null if transverse reinforcement is not present in the RC beam.

In the ACI Building Code [3] it is assumed the critical diagonal crack (CDC) is inclined at an angle of 45 degree. However, data from shear tests performed on RC beams with and without web reinforcement indicate that the CDC inclination depends of several mechanism involved in shear [4], thus the ACI model gives, in general, conservative estimates of shear strength for RC members, mainly when the CDC inclination is less than 45 degree.

The Modified Compression Field Theory (MCFT) was developed by Vecchio and Collins [5]. The MCFT was applied to 102 tested panels and an average ratio between experimental and model results of 1.01 , with a coefficient of variation (COV) of $12.2 \%$, was obtained [6]. Solving the equations of the MCFT to evaluate the shear capacity of a RC member requires an iterative procedure and the knowledge of a relatively high number of parameters, thus Bentz et al. [6] proposed a simplified approach of the MCFT, abbreviated by SMCFT. The SMCFT takes into account the tensile stress factor in the cracked concrete $(\beta)$, and the inclination of the diagonal compressive stress in the web of the section $(\theta)$ to find the shear strength of a section. This model was applied to the same previous 102 RC specimens and an average ratio of experimental to the analytically predicted shear strength $\left(V_{\text {exp. }} / V_{\text {ana. }}\right)$ of 1.11 , with a COV of 
$13.0 \%$, were obtained. In spite of the simple format of the equations for $\beta$ and $\theta$, this model still requires an iterative procedure that introduces extra difficulties in the design perspective.

Recently, Baghi and Barros [7] developed a new method based on the SMCFT and Bianco et al. approach [8] to predict the shear capacity of typical building RC beams shear strengthened according to the near surface mounted (NSM) technique with fiber reinforced polymer (FRP) laminates. This model takes into account the relevant features of the interaction between NSM FRP systems and surrounding concrete, like debonding of FRP laminate/rod and fracture of concrete surrounding the FRP, by considering the inclination of the CDC [9]. In the proposed model, abbreviated by SBBB, two simple equations were proposed for determining directly $\beta$ and $\theta$. This model was applied to a data base composed of 140 beams and an average value of 1.11 with COV of $14.3 \%$ were obtained for the $V_{\text {exp. }} / V_{\text {ana. }}$ ratio. However, the proposed model provided accurate predictions in RC beams with geometric and material properties in the following intervals: $170<d<800 \mathrm{~mm}, 2.4<a / d<4.0,15<f_{c}^{\prime}<80 \mathrm{MPa}, 1.0 \%<\rho_{s l}<3.0 \%$, $0.0<\rho_{s t}+\rho_{f}<1.4 \%$, where $\rho_{s l}$ and $\rho_{s t}$ are the flexural and transverse reinforcement ratio of existing steel bars, respectively, while $\rho_{f}$ is the shear strengthening ratio provided by FRP systems. The interval of these variables are representative of typical RC building beams, but the level of accuracy of this model is not known if applied to beams with relatively high cross section, typical of bridge girders.

The research about the shear resistance of $\mathrm{T}$ cross section beams is relatively limited, and most of the proposed models ignore the favorable effect of the flange for their shear capacity. Bresler and MacGregor [10] indicated that the shear is initiated by the formation of diagonal cracks developing in the shear span, and flexural cracks always form before the occurrence of the diagonal cracks in rectangular, I or T cross section beams. They also showed that the shear capacity and the cracks propagation are influenced by the shape of the section (I and $\mathrm{T}$ section) due to different magnitude of shearing stress developed in the web. However, international codes, such as ACI Building Code [3] and Eurocode [11], neglect the influence of the flange in $\mathrm{T}$ cross section beams, and the shear force in RC T-beams is assumed to be carried only by the web.

This paper aims to propose a design oriented approach capable of predicting with acceptable predictive performance the shear capacity of rectangular and $\mathrm{T}$ cross shape $\mathrm{RC}$ beams. For this purpose, a sensitivity analysis is carried out for assessing the relative importance of each input parameter that affects the shear capacity of RC beams according to the SMCFT. Based on the results, equations for obtaining $\beta$ and $\theta$ without any iterative procedure are derived. In 
addition, based on the results in literature, a parameter is proposed to predict the influence of the flange of the $\mathrm{T}$ cross section beams on their shear capacity. To assess the predictive performance of the proposed model, a data base (DB) composed of $349 \mathrm{RC}$ beams is set, and the model's performance is appraised. The results obtained with the proposed approach are compared to the ones determined with ACI, SMCFT, and SBBB model.

\section{Simplified Modified Compression Field Theory [6]}

According to the SMCFT, the shear capacity of a RC beam $(v)$ is obtained by the following equation:

$$
v=v_{c}+v_{s}=\beta \cdot \sqrt{f_{c}^{\prime}}+\rho_{s t} \cdot f_{s t, y} \cdot \cot \theta
$$

where $v_{c}$ and $v_{s}$ are the shear strength provided by concrete and transverse steel reinforcement, respectively, and $\rho_{s t}$ is:

$$
\rho_{s t}=\frac{A_{s t}}{b_{w} \cdot \mathrm{s}}
$$

In equation (3), $\beta$ is the tensile stress factor in the cracked concrete, and $\theta$ is the inclination of the diagonal compressive stress in the web of the beam's cross section, which are obtained from the following respective equations:

$$
\begin{aligned}
& \beta=\frac{0.4}{1+1500 \varepsilon_{s l}} \frac{1300}{1000+s_{x e}} \\
& \theta=\left(29+7000 \varepsilon_{s l}\right)\left(0.88+\frac{s_{x e}}{2500}\right) \leq 75^{\circ}
\end{aligned}
$$

where

$$
s_{x e}=\frac{35 s_{x}}{a_{g}+16} \geq 0.85 s_{x}
$$

represents physically the crack spacing, being $s_{x}$ the vertical distance between longitudinal reinforcement, while $a_{g}$ is the maximum dimension of aggregates. If the longitudinal reinforcement is not yielded, the axial strain of the longitudinal reinforcement, $\varepsilon_{s l}$, can be obtained from the following equation:

$$
\varepsilon_{s l}=\frac{f_{s l}}{E_{s l}}=\frac{v \cot \theta-v_{c} / \cot \theta}{E_{s l} \rho_{s l}}
$$

where $E_{s l}$ is the modulus of elasticity of the longitudinal reinforcement.

The solution procedure to calculate the shear strength of a concrete beam, according to the SMCFT, is based on the following steps: 
Step 1: Input parameters $\left(E_{s l}, \rho_{s l}, f_{c}^{\prime}, \rho_{s t}, f_{s t, y}, a_{g}, \varepsilon_{s l, y}\right.$, and $\left.s_{x}\right)$;

Step 2: Calculate the crack spacing using equation (7);

Step 3: Assume a value for $\varepsilon_{s l}$;

Step 4: Calculate $\beta$ and $\theta$ using equations (5) and (6), respectively.

Step 5: Calculate the shear strength based on equation (3).

Step 6: Calculate the longitudinal strain, $\varepsilon_{s l}$, according to equation (8).

Step 7: Evaluate the normalized absolute difference between the strain values for the longitudinal reinforcement obtained in Steps 3 and 6 divided by the yield strain of the longitudinal reinforcement, $\left|\varepsilon_{s l}^{q+1}-\varepsilon_{s l}^{q}\right| / \varepsilon_{s l, y}$.

Step 8: If the value obtained in Step 7 is less than a certain adopted tolerance the iterative procedure is concluded, otherwise is return to Step 3 with the $\varepsilon_{s l}$ determined in Step 6, and this process is executed up to obtain convergence. More information about this method can be found in $[6,9]$.

\section{SBBB model [7]:}

In the SBBB model the shear strength of a RC beam is obtained according to equation (3), but $\beta$ and $\theta$ are determined by the following equations:

$$
\begin{gathered}
\beta_{s}=-0.14 \times x_{s}^{0.21}+0.13 \times y_{s}^{0.15} \quad 0.052<\beta_{s}<0.36 \\
\theta_{s}=3.36 \times \beta_{s}^{-0.82}+21.5 \quad 29^{\circ} \leq \theta_{s} \leq 60^{\circ}
\end{gathered}
$$

where $x_{s}=\left(\rho_{s t} f_{s t, y}\right) / f_{c}^{\prime}$ and $y_{s}=\left(\rho_{s l} E_{s l}\right) / f_{c}^{\prime}$. As mentioned before, this approach was calibrated exclusively for predicting the shear capacity of typical RC building beams.

\section{Sensitivity analysis}

Sensitivity analysis means to study the effect of input parameters $\left(d, b_{w}, f_{c}^{\prime}, a_{g}, E_{s l}, \rho_{s l}, \bar{\sigma}_{s t}=\rho_{s t} \times f_{s t, y}\right)$ on the objective function (shear capacity of RC beams, equation (3)). There are two approaches to execute sensitivity analysis: local and global sensitivity analysis. Local sensitivity analysis evaluates the objective function by changing one parameter and keeping other parameters fixed. This analysis is efficient for simple objective function, but it neglects the influence of the interaction between parameters on the objective function [12]. In the global sensitivity analysis, the objective function is evaluated by varying all the parameters simultaneously, which takes into account the influence of the interaction between parameters on the objective function [13]. Global analysis is an appropriate 
option for sensitivity analysis of SMCFT due to the iterative nature and complexity of the model. Monte Carlo method can be regarded as a Global sensitivity analysis. This method is a process of running the objective function numerous times with a random selection of each input parameter simultaneously.

A sensitivity analysis is carried out to assess the relative importance of each input parameter on the shear capacity of $\mathrm{RC}$ beams (equation (3)) in order to figure out what are the input parameters that most affect the result. All of the input parameters are characterized by a uniform probability distribution, which means a range of possible values with the same likelihood of occurrence (Table 1).

For sensitivity analysis, equation (3) is implemented in a spreadsheet that is re-calculated 500,000 times, each time with a set of random new possible values of the input parameters. The number of samples $(500,000)$ is adopted to cover all possible scenarios for RC beams in the built environment.

To measure the influence of each input parameter on the results of $v$ (equation (3)), $\beta$ and $\theta$, the dimensionless coefficient of correlation

$$
r=\frac{n \sum_{i=1}^{n} x_{i} y_{i}-\left(\sum_{i=1}^{n} y_{i}\right)\left(\sum_{i=1}^{n} x_{i}\right)}{\sqrt{n\left(\sum_{i=1}^{n} x_{i}^{2}\right)-\left(\sum_{i=1}^{n} x_{i}\right)^{2}} \sqrt{n\left(\sum_{i=1}^{n} y_{i}^{2}\right)-\left(\sum_{i=1}^{n} y_{i}\right)^{2}}}
$$

is evaluated, where $n$ is the number of the samples, $x_{i}$ is the input parameter and $y_{i}$ is the output (value of equation (3), $\beta$ and $\theta$ ). The $r$ varies between -1 and +1 . Positive value of $r$ means a positive linear correlation, which indicates that the objective function $(y)$ increases with the input parameter $(x)$, and vice versa. A negative value of $r$ means a negative linear correlation, which indicates a decrease of $y$ with the increase of $x$, or an increase of $y$ with a decrease of $x$. When $r$ is closed to 0 it means no linear correlation, or a weak linear correlation, exists. According to this definitions, the influence of the input parameters $\left(d, b_{w}, f_{c}^{\prime}, a_{g}, E_{s l}, \rho_{s l}, \rho_{s t} \times f_{s t, y}\right)$ on the objective function (equation (3), $\beta$ and $\theta$ ) are presented in Figure 1. The obtained results demonstrate, $d$ has a negative linear correlation on the $v$, which means when $d$ increases $v$ decreases, which is a consequence of size effect [14]. The remain considered parameters have positive linear correlation on the $v$ (apart $b_{w}$ that has almost null influence), mainly $\rho_{s l}$ and $\bar{\sigma}_{s t}$, since the favorable dowel effect increases with $\rho_{s l}$ and the contribution of steel 
stirrups increases with $\bar{\sigma}_{s t}$. As expected, the considered parameters have opposite linear correlation on the $\beta$ and $\theta$

According to the results presented in Figure 1, the relationship between $\beta v s . \bar{\sigma}_{s t} / f_{c}^{\prime}$ and $\left(\rho_{s l} \times E_{s l}\right) / f_{c}^{\prime} \times\left(b_{w} / d\right)$ for 500,000 generated samples with Monte Carlo simulation are presented in Figure 2. These results can be approximated by a surface defined by the following equation:

$$
\beta_{N B B}=0.65 \times\left(-0.3 \times x^{0.5}+0.15 \times y^{0.15}\right) \quad 0.035<\beta_{N B B}<0.39
$$

where $x$ and $y$ are $\bar{\sigma}_{s t} / f_{c}^{\prime}$ and $\left(200000 \times \rho_{s l}\right) / f_{c}^{\prime} \times\left(b_{w} / d\right)$, respectively. In this equation $f_{c}^{\prime}$ and $\rho_{s t} \times f_{s t, y}$ are in MPa. The Sum of Squares due to Error (SSE), R-square, and Root Mean Squared Error (RMSE) for this fitted surface are $465,0.56$, and 0.03 , respectively, which indicate the good fit of the model to the generated samples. More information about these Goodness-of-Fit Statistics can be found in [7].

The relationship between $\beta_{N B B}$ and $\theta_{N B B}$ is presented in Figure 3. This relationship is defined by the following equation:

$$
\theta_{N B B}=4 \times \beta_{N B B}^{-0.7}+22 \quad 28^{\circ} \leq \theta_{N B B} \leq 75^{\circ}
$$

The SSE, R-square and RMSE for this fitted curve are 730000, 0.99, and 1.2, respectively. In Figure 2 the results are fitted for 2 variables ( $x$ and $y$ ), but in Figure 3 the results are fitted for just one variable. Hence, it is reasonable the Rsquare value for $\beta_{N B B}$ is not so good as the one of $\theta_{N B B}$.

\section{Effects of flange in T-beams}

As already mentioned, most of existing models neglect the effect of flange in $\mathrm{T}$ cross section beams on the shear load carrying capacity. Thamrin et al. [15] proposed a simplified equation for the T-beams without shear reinforcement. For simulating the effect of beam's flange on the shear capacity they suggested the following coefficient:

$$
\alpha=1.0+\frac{b \cdot h_{f}}{4 d^{2}}
$$

where $b$ and $h_{f}$ are the width and the thickness of the flange (Figure 4). The $\alpha$ is multiplied by the square root of the concrete compressive strength. However, this coefficient gives conservative estimations of the effect of the flange for the shear capacity of $\mathrm{T}$ cross section beams (Figure 5a). RILEM TC162-TDF [16] recommendations take into account the influence of the flanges on the shear capacity of $\mathrm{T}$ cross section beams by introducing the following coefficient that is multiplied by the square root of the concrete compressive strength: 


$$
k_{f}=1+n \cdot\left(h_{f} / b_{w}\right) \cdot\left(h_{f} / d\right) \leq 1.5
$$

where

$$
n=\left(b-b_{w}\right) / h_{f} \leq 3
$$

This equation takes into account the shaded part of the flange as shown in Figure 4a, but provides unconservative results (Figure 5b). Thus, the following equation is suggested by considering half of the shaded part of the flange for the shear contribution (Figure 4b):

$$
k_{f n}=1+n \times 0.5 \times\left(h_{f} / b_{w}\right) \times\left(h_{f} / d\right) \leq 1.5
$$

where $n$ is obtained by equation (15b). The contribution of the flange to the beam's shear capacity is null in beams of rectangular cross section since $b=b_{w}$. This coefficient affects the $v_{c}$ in equation (3):

$$
v=v_{c}+v_{s}=k_{f} \cdot \beta_{N B B} \cdot \sqrt{f_{c}^{\prime}}+\rho_{s t} \cdot f_{s t, y} \cdot \cot \theta_{N B B}
$$

\section{Assessment of the predictive performance of the developed model}

An extensive data base (DB) containing $349 \mathrm{RC}$ beams failing in shear [9, 17-35] was collected from published literature to appraise the predictive performance of the developed approach. This DB includes beams of different size, longitudinal and transverse steel reinforcement ratios, concrete compressive strength, and a wide range of shear span ratio to effective depth $(a / d)$. The collected beams have the following interval of values for the relevant model's parameters: $50 \leq b_{w} \leq 460 \mathrm{~mm} ; 0 \leq h_{f} \leq 280 \mathrm{~mm} ; 125 \leq b \leq 1450 \mathrm{~mm} ; 200 \leq d<1370 \mathrm{~mm} ; 2.4 \leq a / d<17.03 ; 10 \leq f_{c}^{\prime}$ $<125 \mathrm{MPa}, 0.5 \% \leq \rho_{s l}<15.7 \%$, and $0.0 \leq \rho_{s t} \times f_{s t, y}<16.7 \mathrm{MPa}$. The DB contains values from experiments performed on 116 beams with $\mathrm{T}$ cross section $\left(k_{f}>1.0\right)$, and 234 beams with rectangular cross section $\left(k_{f}=1.0\right)$. The DB includes 82 beams without shear reinforcement $\left(\bar{\sigma}_{s t}=0\right)$. The sample distribution of the all collected data is presented in Figure 6.

Figure 7 represents the $V_{\text {exp. }} / V_{\text {ana. }}$ of the $\mathrm{T}$ cross section beams for the two scenarios in terms of considering $\left(w-k_{f}\right.$ ), or not $\left(w-o-k_{f}\right)$, the contribution of the flange for the beam's shear capacity, i.e., by taken in equation (17) the $k_{f}$ according to equation (16). The average value of $\left(V_{\text {exp. }} / V_{\text {ana. }}\right)_{w-o-k_{f}}$ is 1.36 with a COV of $17.7 \%$, while using the new approach (herein designated by NBB) that considers the contribution of the beam's flange for the shear resistance 
(equation (17)), an average value of 1.17 with a $\mathrm{COV}$ of $15.1 \%$ for the $\left(V_{\text {exp. }} / V_{\text {ana. }}\right)_{w-k_{f}}$ ratio were obtained, which indicate the efficiency of the proposed model to predict the shear strength of T-cross section beams. For the NBB, ACI [3], SMCFT [6], and SBBB [7] approaches, the obtained values of $V_{\text {ana. }}$ are compared with $V_{\text {exp. }}$ of the $\mathrm{DB}$, and the values of $V_{\text {exp. }} / V_{\text {ana. }}$ ratio are included in Table 2 and represented in Figures 8 and 9. The NBB model has assured an average value of $V_{\text {exp. }} / V_{\text {ana. }}$ of 1.24 for all the 349 beams with a COV of $20.9 \%$. The ACI model has an average value of $V_{\text {exp. }} / V_{\text {ana. }}$ of 1.42 with COV of $27.0 \%$. The SBBB and SMCFT have an average value of 1.01 and 1.09 , respectively, with COV of $25 \%$ and $27 \%$.

The predictive performance of the adopted approaches is being detrimentally affected due to some abnormal results reported in some literature that conducted to the DB with 349 beams. Due to the suspicious that some problems have occurred in the experimental programs of these beams, the corresponding results were removed from the DB, resulting a reduced $\mathrm{DB}(\mathrm{RDB})$ of 300 beams. A RC beam was removed if:

a) showed poor performance in all the design models ( $\left.V_{\text {exp. }} / V_{\text {ana. }} \leq 0.85\right)$;

b) $a / d>10$ (high probability of has been failed in bending);

c) $\rho_{s t} \times f_{s t, y}>5 \mathrm{MPa}$ (abnormal high percentage of transverse reinforcement, where flexural failure mode is expected to have occurred);

d) $\rho_{s l}>5 \%$ (abnormal high percentage of longitudinal reinforcement, providing unrealistic dowel effect resisting mechanism);

e) $k_{f}>1.5$ (in order to respect the condition provided by equation (15a);

The results of the RDB are presented in Figure 10. The NBB model has assured an average value of $V_{\text {exp. }} / V_{\text {ana. }}$ of 1.25 for RDB with a COV of $19 \%$. The ACI, SBBB and SMCFT models have an average value of $V_{\text {exp. }} / V_{\text {ana. }}$ of 1.44 , 1.04 , and 1.10 with COV of $24.0 \%, 22 \%$, and $22 \%$, respectively. A modified version of the Demerit Points Classification (DPC) [36] proposed by Collins [37] is presented, where a penalty (PEN) is assigned to each range of $V_{\text {exp. }} / V_{\text {ana. }}$ parameter according to Table 3 , and the performance of each approach is determined by the total of penalties (Total PEN).

According to the results included in Tables 4 and 5, the predictive performance of NBB model is better than of the other models in both DB and RDB since its total penalties is the smallest one in both scenarios, which is justified by 
the larger number of predictions in the appropriate safety and conservative intervals according to the DPC (Table 3). According to Table 4, the NBB model has 329 samples in appropriate safety and conservative intervals, while ACI, SMCFT, and SBBB have 307, 290, and 260 samples, respectively. The major difference between the NBB and the other models is in extremely dangerous interval $\left(V_{\text {exp. }} / V_{\text {ana. }}<0.5\right)$, since this model does not have any sample in this interval, while ACI, SMCFT, and SBBB have 5, 6, 9 samples, respectively.

Figure 11 represents graphically the influence of the following parameters (assumed the most relevant for the shear strength of a RC beam) on the predictive performance of the NBB approach: $f_{c}^{\prime}, b_{w} / d, \rho_{s l}, \rho_{s t} \times f_{s t, y}$, and $A_{f} / A_{t}$,

where $A_{f} / A_{t}$ is the ratio between the area of the flange $\left(b \times h_{f}\right)$ and total area of the beam's cross section. Besides the good predictive performance of the NBB approach, this figure shows that no significant trend exists with respect to the design parameters, indicating their influence is being properly considered in the proposed model.

\section{Conclusion}

This paper presented a design oriented model based on the simplified modified compression field theory (SMCFT) to predict the shear capacity of reinforced concrete (RC) beams. A global sensitivity analysis (Monte Carlo simulation) with 500,000 generated samples was carried out to assess the relative importance of each input parameter on the shear capacity of the RC beams. Based on the results of the sensitivity analysis, two simple equations were proposed to directly determine the tensile stress factor in cracked concrete $(\beta)$ and the inclination of the diagonal compressive stress in the web of the section $(\theta)$. These two equations were integrated into the SMCFT equation, which was coupled with an already published analytical formulation to derive a new approach (designated by NBB) for the prediction of the shear capacity of RC beams. A coefficient was introduced to take into account the effect of the flange of a $\mathrm{T}$ cross section beam on its shear capacity. The obtained results indicated the efficiency of the proposed model to predict the shear strength of the T-cross section beams.

A data base composed of $349 \mathrm{RC}$ beams, which according to the authors were assumed failing in shear, was set to appraise the predictive performance of the proposed model, and the results were compared to the ones provided by ACI, SMCFT, and SBBB models. By evaluating the ratio between the experimental results and the analytical predictions ( $V_{\text {exp. }} / V_{\text {ana. }}$ ), an average value of 1.24 , with a coefficient of variation (COV) $20.9 \%$ was obtained by using the NBB without any prediction in extremely dangerous interval according to Demerit Points Classification. The 
average value of $V_{\text {exp. }} / V_{\text {ana. }}$ for ACI, SBBB, and SMCFT models was, respectively, 1.49, 1.01, and 1.09, with COV of $27.0 \%, 25.0 \%$, and $25.0 \%$.

\section{Acknowledgements:}

The second author wish to acknowledge the grant SFRH/BSAB/114302/2016 provided by FCT.

\section{References:}

1. Baghi, H., Shear strengthening of reinforced concrete beams with SHCC-FRP panels. 2015, University of Minho.

2. Belarbi, A., Zomorodian, M., Yang, G., Acun, B., PURE SHEAR TESTS ON FRP STRENGTHENED MEMBRANE ELEMENTS, in Conference of Structural Failure. 2015: Szczecin-Miedzyzdrije.

3. ACI Committee, A.C.I., \& International Organization for Standardization, Building code requirements for structural concrete (ACI 318-08) and commentary. 2011, American Concrete Institute.

4. $\quad$ Roller, J.J., Russell, H.G., Shear Strength of High-Strength Concrete Beams with Web Reinforcement. ACI Structural Journal, 1990. 87(2): p. 191-198.

5. $\quad$ Vecchio, F.J., Collins, M.P., The Modified Compression-Field Theory for Reinforced Concrete Elements Subjected to Shear. ACI Journal, 1986. 83(2): p. 219-231.

6. $\quad$ Bentz, E.C., Vecchio, F.J., Collins, M.P., Simplified Modified Compression Field Theory for Calculating Shear Strength of Reinforced Concrete Elements. ACI STRUCTURAL JOURNAL, 2006. 103: p. 614-624.

7. Baghi, H., Barros, J.A.O., Design Approach to Determine Shear Capacity of Reinforced Concrete Beams Shear Strengthened with NSM Systems. Journal of Structural Engineering, 2017. 10.1061/(ASCE)ST.1943$541 X .0001793$.

8. Bianco, V., Monti, G., Barros, J.A.O., Design formula to evaluate the NSM FRP strips shear strength contribution to a RC beam. Composites Part B: Engineering, 2013. 56: p. 960-971.

9. Baghi, H., Barros, A.O. Joaquim,, New Approach to Predict Shear Capacity of Reinforced Concrete Beams Strengthened with Near-Surface-Mounted Technique. ACI Structural Journal, 2017. 114(1): p. 137-148.

10. Bresler, B., MacGregor, J.G.,, Review of concrete beams failing in shear. Journal of Structural Division (ASCE), 1967. 93(ST1): p. 343-372.

11. British Standards Institution, Eurocode 2: Design of Concrete Structures: Part 1-1: General Rules and Rules for Buildings. 2001, British Standards Institution.

12. MathWorks, What Is Sensitivity Analysis? 2016, MathWorks.

13. Gilman, J.R., Brickey, R.T., and Red, M.M., Monte Carlo Techniques for Evaluating Producing Properties. Society of Petroleum Engineers, 1998. https://doi.org/10.2118/39926-MS.

14. Bazant, P.Z., Size effect on structural strength: a review. Archive of Applied Mechanics, 1999. 69: p. 703725 .

15. Thamrin, R., Tanjung, J., Aryanti, R., Nur, O.F., Devinus, A.,, Shear Strength of Reinforced Concrete TBeams without Stirrups. Journal of Engineering Science and Technology, 2016. 11(4): p. 548-562.

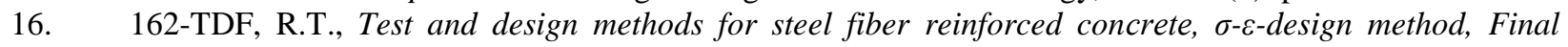
Recommendation. Materials and Structures, 2003. 36(October 2003): p. 560-567.

17. Dias, S.J.E., Barros, J.A.O., Shear strengthening of RC beams with NSM CFRP laminates: Experimental research and analytical formulation. Composite Structures, 2013. 99: p. 477-490.

18. Chaallal, O., Mofidi, A., Benmokrane, B., Neale, K., Embedded Through-Section FRP Rod Method for Shear Strengthening of RC Beams: Performance and Comparison with Existing Techniques. Composites for Construction, 2011. 19: p. 374-383.

19. De Lorenzis, L., Nanni, A., Shear Strengthening of Reinforced Concrete Beams with Near-Surface Mounted Fiber-Reinforced Polymer Rods. ACI Structural Journal, 2001. 98: p. 60-68.

20. Kong, P.Y.L., Rabgan, V.,, Shear strength of high-performance concrete beams. ACI structural journal, 1998. 95(6): p. 677-687.

21. Frosch, R., Behavior of Large-Scale Reinforced Concrete Beams with Minimum Shear Reinforcement. ACI Structural Journal, 2001. 97(6): p. 814-820. 
22. Sagaseta, J., Vollum, R.L.,, Influence of beam cross section, loading, arrangement and aggregare type on shear strength. Magazine of concrete research, 2011. 63(2): p. 139-155.

23. Thamrin, R., Tanjung, J., Aryanti, R., Fitrah, O., Devinus, A.,, Shear Strength of Reinforced Concrete TBeam without Stirrups. Journal of Engineering Science and Technology, 2016. 11(4): p. 548-562.

24. Yoon, Y., Cook, W., Mitchell, D., Minimum Shear Reinforcement in Normal, Medium, and High Strength Concrete Beams. ACI Structural Journal, 1996. 93(5): p. 576-584.

25. Roller, J., Russell, H.,, Shear Strength of High-Strength Concrete Beams with Web Reinforcement. ACI Structural Journal, 1991. 78(2): p. 191-198.

26. Johnson, M., Ramirez, J., Minimum Shear Reinforcement in Beams with higher Strength Concrete. ACI Structural Journal, 1989. 86(4): p. 376-382.

27. Reineck, K., Bentz, E., Fitik, B., Kuchma, D., Bayrak., , ACI-DAfStb Databases for Shear Tests on Slender Reinforced Concrete Beams with Stirrups. ACI Structural Journal, 2014. 111(5): p. 1147-1156.

28. Hsiung, W., Frantz, G.C.,, TRANSVERSE STIRRUP SPACING IN R/C BEAMS. Journal of Structural Engineering (ASCE), 1984. 111(2): p. 353-362.

29. Mphonde, A.G., Use of Stirrup Effectiveness in Shear Design of Concrete Beams. ACI Structural Journal, 1989. 86(5): p. 541-545.

30. Sarsam, K.F., Al-Musawi, J.M.S., Shear Design of High-and Normal Strength Concrete Beams with Web Reinforcement. ACI Structural Journal, 1990. 89(6): p. 658-664.

31. Ozcebe, G., Ersoy, U., Tankut, T., Evaluation of Minimum Shear Reinforcement Requirements for Higher Strength Concrete. ACI Structural Journal, 1999. 96(3): p. 361-369.

32. Angelakos, D., Bentz, E., Collins, M.,, Effect of Concrete Strength and Minimum Stirrups on Shear Strength of Large Members. ACI Structural Journal, 2001. 98(3): p. 290-300.

33. Bresler, B., Scordelis, A.C.,, Shear Strength of Reinforced Concrete Beams. JOURNAL OF THE AMERICAN CONCRETE INSTITUTE, 1963. 60(4): p. 51-74.

34. Lee, J., Choi, I., Kim, S.,, Shear Behavior of Reinforced Concrete Beams with High-Strength Stirrups. ACI Structural Journal, 2011. 108(5): p. 620-629.

35. Krefel, W., J., Thurston, C.W., Studies of the Shear and Diagonal Tension Strength of Simply Supported Reinforced Concrete Beams. ACI Structural Journal, 1966. 63(21): p. 451-476.

36. Moraes Neto, B., Barros, J., Melo, G., Model to Simulate the Contribution of Fiber Reinforcement for the Punching Resistance of RC Slabs. Journal of Materials in Civil Engineering, 2014. 26(7).

37. Collins, M.P., Evaluation of shear design procedures for concrete structures, A.R.p.f.t.C.t.c.o.r.c. design, Editor. 2001. 
Table 1: Values characterizing the uniform probability distribution of the input parameters.

\begin{tabular}{|c||c|c||c|c|c|c|c|}
\hline & $\begin{array}{c}h_{w} \\
(\mathrm{~mm})\end{array}$ & $\begin{array}{c}b_{w} \\
(\mathrm{~mm})\end{array}$ & $\begin{array}{c}f_{c}^{\prime} \\
(\mathrm{MPa})\end{array}$ & $\begin{array}{c}a_{g} \\
(\mathrm{~mm})\end{array}$ & $\begin{array}{c}E_{s l} \\
(\mathrm{GPa})\end{array}$ & $\begin{array}{c}\rho_{s l} \\
(\%)\end{array}$ & $(\mathrm{MPa})$ \\
\hline Range of variation & $200-1600$ & $50-500$ & $10-120$ & $10-40$ & $180-220$ & $0.5-5$ & $0-5$ \\
\hline
\end{tabular}


Table 2: Summary of experimental and analytical results applied to the DB

\begin{tabular}{|c|c|c|c|c|c|c|c|c|c|c|c|c|c|c|}
\hline Beam label & $\begin{array}{c}b_{w} \\
(m m)\end{array}$ & $\begin{array}{c}d \\
(m m)\end{array}$ & $\begin{array}{c}h_{f} \\
(\mathrm{~mm})\end{array}$ & $\begin{array}{c}b \\
(m m)\end{array}$ & $a / d$ & $\begin{array}{c}f_{c}^{\prime} \\
(M P a)\end{array}$ & $\begin{array}{l}\rho_{s l} \\
(\%)\end{array}$ & $\rho_{s t} \times f_{s t, y}$ & $V(k N)$ & $k_{f}$ & $\frac{V_{\text {exp. }}}{V_{N B B}}$ & $\frac{V_{\text {exp. }}}{V_{S B B B}}$ & $\frac{V_{\text {exp. }}}{V_{\text {SMCFT }}}$ & $\frac{V_{\text {exp. }}}{V_{A C I}}$ \\
\hline \multicolumn{15}{|c|}{ Dias and Barros [17] } \\
\hline$C-R-I$ & 180 & 360 & 100 & 450 & 2.5 & 39.7 & 2.8 & 0.0 & 124 & 1.21 & 1.36 & 1.11 & 1.11 & 1.79 \\
\hline $2 S-R-I$ & 180 & 360 & 100 & 450 & 2.5 & 39.7 & 2.8 & 0.569 & 182 & 1.21 & 1.40 & 1.26 & 1.20 & 1.71 \\
\hline $7 S-R-I$ & 180 & 360 & 100 & 450 & 2.5 & 39.7 & 2.8 & 1.512 & 280 & 1.21 & 1.39 & 1.23 & 1.27 & 1.67 \\
\hline $4 S-R-I I$ & 180 & 360 & 100 & 450 & 2.5 & 39.7 & 2.8 & 0.948 & 223 & 1.21 & 1.41 & 1.25 & 1.24 & 1.70 \\
\hline$C-R-I I I$ & 180 & 360 & 100 & 450 & 2.5 & 18.6 & 2.8 & 0 & 88 & 1.21 & 1.26 & 1.03 & 1.07 & 1.85 \\
\hline $2 S-R-I I I$ & 180 & 360 & 100 & 450 & 2.5 & 18.6 & 2.8 & 0.566 & 136 & 1.21 & 1.24 & 1.09 & 1.08 & 1.62 \\
\hline $4 S-R-I I I$ & 180 & 360 & 100 & 450 & 2.5 & 18.6 & 2.8 & 0.938 & 182 & 1.21 & 1.32 & 1.14 & 1.17 & 1.68 \\
\hline$C-R-I V$ & 180 & 356 & 100 & 450 & 2.5 & 31.1 & 2.9 & 0 & 146 & 1.21 & 1.75 & 1.43 & 1.44 & 2.40 \\
\hline $2 S-R-I V$ & 180 & 356 & 100 & 450 & 2.5 & 31.1 & 2.9 & 0.560 & 189 & 1.21 & 1.56 & 1.39 & 1.34 & 1.96 \\
\hline $6 S-R-I V$ & 180 & 356 & 100 & 450 & 2.5 & 31.1 & 2.9 & 1.284 & 246 & 1.21 & 1.40 & 1.23 & 1.26 & 1.72 \\
\hline$C-R-V$ & 180 & 360 & 100 & 450 & 3.33 & 59.4 & 3.1 & 0 & 126 & 1.21 & 1.18 & 0.97 & 0.94 & 1.48 \\
\hline $3 S-R-V$ & 180 & 360 & 100 & 450 & 3.33 & 59.4 & 3.1 & 0.578 & 180 & 1.21 & 1.24 & 1.12 & 1.04 & 1.47 \\
\hline $5 S-R-V I$ & 180 & 360 & 100 & 450 & 3.33 & 59.4 & 3.1 & 0.865 & 205 & 1.21 & 1.23 & 1.11 & 1.06 & 1.45 \\
\hline \multicolumn{15}{|c|}{ Chaallal et al. [18] } \\
\hline SO-CON-I & 152 & 350 & 102 & 508 & 3 & 25 & 3.7 & 0 & 81 & 1.29 & 1.17 & 1.00 & 1.00 & 1.79 \\
\hline S1-CON-I & 152 & 350 & 102 & 508 & 3 & 25 & 3.7 & 2.030 & 232 & 1.29 & 1.21 & 1.03 & 1.10 & 1.51 \\
\hline S3-CON-II & 152 & 350 & 102 & 508 & 3 & 35 & 3.7 & 1.631 & 195 & 1.29 & 1.11 & 0.97 & 1.00 & 1.39 \\
\hline \multicolumn{15}{|c|}{ De Lorenzis and Nanni [19] } \\
\hline$B V$ & 152 & 356 & 102 & 508 & 3 & 31 & 2.4 & 0 & 91 & 1.29 & 1.28 & 1.09 & 1.11 & 1.78 \\
\hline$B S V$ & 152 & 356 & 102 & 508 & 3 & 31 & 2.4 & 1.003 & 153 & 1.29 & 1.19 & 1.06 & 1.08 & 1.45 \\
\hline \multicolumn{15}{|c|}{ Baghi and Barros [7] } \\
\hline$C-R-I I$ & 180 & 360 & 100 & 450 & 2.5 & 32.7 & 2.8 & 0 & 128 & 1.21 & 1.50 & 1.23 & 1.24 & 2.03 \\
\hline $7 S-R-I I$ & 180 & 360 & 100 & 450 & 2.5 & 32.7 & 2.8 & 1.395 & 318 & 1.21 & 1.70 & 1.49 & 1.54 & 2.07 \\
\hline \multicolumn{15}{|c|}{ Kong and Rangan [20] } \\
\hline$S 1-1$ & 250 & 292 & 0 & 250 & 2.5 & 63.6 & 2.8 & 0.893 & 228 & 1.00 & 1.24 & 1.08 & 1.04 & 1.39 \\
\hline$S 2-2$ & 250 & 292 & 0 & 250 & 2.5 & 72.5 & 2.8 & 0.717 & 232 & 1.00 & 1.34 & 1.17 & 1.09 & 1.47 \\
\hline$S 2-3$ & 250 & 292 & 0 & 250 & 2.5 & 72.5 & 2.8 & 0.893 & 253 & 1.00 & 1.34 & 1.17 & 1.12 & 1.48 \\
\hline$S 2-5$ & 250 & 292 & 0 & 250 & 2.5 & 72.5 & 2.8 & 1.190 & 282 & 1.00 & 1.31 & 1.15 & 1.13 & 1.46 \\
\hline S3-1 & 250 & 297 & 0 & 250 & 2.49 & 67.4 & 1.66 & 0.638 & 209 & 1.00 & 1.35 & 1.18 & 1.14 & 1.38 \\
\hline S4-1 & 250 & 542 & 0 & 250 & 2.40 & 87.3 & 3.02 & 0.893 & 354 & 1.00 & 1.04 & 0.84 & 0.79 & 1.05 \\
\hline$S 4-2$ & 250 & 444 & 0 & 250 & 2.41 & 87.3 & 2.96 & 0.893 & 286 & 1.00 & 1.00 & 0.84 & 0.79 & 1.04 \\
\hline$S 4-3$ & 250 & 346 & 0 & 250 & 2.40 & 87.3 & 2.84 & 0.893 & 243 & 1.00 & 1.07 & 0.92 & 0.86 & 1.13 \\
\hline$S 4-4$ & 250 & 292 & 0 & 250 & 2.50 & 87.3 & 2.80 & 0.893 & 258 & 1.00 & 1.32 & 1.16 & 1.09 & 1.42 \\
\hline S4-6 & 250 & 198 & 0 & 250 & 2.53 & 87.3 & 2.79 & 0.893 & 203 & 1.00 & 1.46 & 1.34 & 1.27 & 1.65 \\
\hline
\end{tabular}




\begin{tabular}{|c|c|c|c|c|c|c|c|c|c|c|c|c|c|c|}
\hline Beam label & $\begin{array}{c}b_{w} \\
(m m)\end{array}$ & $\begin{array}{c}d \\
(m m)\end{array}$ & $\begin{array}{c}h_{f} \\
(\mathrm{~mm})\end{array}$ & $\begin{array}{c}b \\
(m m)\end{array}$ & $a / d$ & $\begin{array}{c}f_{c}^{\prime} \\
(M P a)\end{array}$ & $\begin{array}{l}\rho_{s l} \\
(\%)\end{array}$ & $\rho_{s t} \times f_{s t, y}$ & $V(k N)$ & $k_{f}$ & $\frac{V_{\text {exp. }}}{V_{N B B}}$ & $\frac{V_{\text {exp. }}}{V_{S B B B}}$ & $\frac{V_{\text {exp. }}}{V_{S M C F T}}$ & $\frac{V_{\text {exp. }}}{V_{A C I}}$ \\
\hline S6-5 & 250 & 299 & 0 & 250 & 2.64 & 68.9 & 3.69 & 0.638 & 297 & 1.00 & 1.71 & 1.47 & 1.34 & 1.94 \\
\hline S7-1 & 250 & 294 & 0 & 250 & 3.3 & 74.8 & 4.5 & 0.597 & 217 & 1.00 & 1.24 & 1.06 & 0.95 & 1.43 \\
\hline S7-2 & 250 & 294 & 0 & 250 & 3.3 & 74.8 & 4.5 & 0.699 & 205 & 1.00 & 1.11 & 0.96 & 0.86 & 1.29 \\
\hline S7-3 & 250 & 294 & 0 & 250 & 3.3 & 74.8 & 4.5 & 0.893 & 246 & 1.00 & 1.22 & 1.05 & 0.97 & 1.42 \\
\hline S7-4 & 250 & 294 & 0 & 250 & 3.3 & 74.8 & 4.5 & 1.115 & 273 & 1.00 & 1.23 & 1.07 & 1.00 & 1.44 \\
\hline$S 7-5$ & 250 & 294 & 0 & 250 & 3.3 & 74.8 & 4.5 & 1.275 & 304 & 1.00 & 1.28 & 1.12 & 1.06 & 1.51 \\
\hline S7-6 & 250 & 294 & 0 & 250 & 3.3 & 74.8 & 4.5 & 1.491 & 311 & 1.00 & 1.21 & 1.06 & 1.02 & 1.43 \\
\hline S8-1 & 250 & 292 & 0 & 250 & 2.5 & 74.6 & 2.8 & 0.597 & 272 & 1.00 & 1.66 & 1.44 & 1.33 & 1.80 \\
\hline$S 8-2$ & 250 & 292 & 0 & 250 & 2.5 & 74.6 & 2.8 & 0.717 & 251 & 1.00 & 1.44 & 1.25 & 1.17 & 1.57 \\
\hline S8-3 & 250 & 292 & 0 & 250 & 2.5 & 74.6 & 2.8 & 0.893 & 265 & 1.00 & 1.40 & 1.22 & 1.16 & 1.54 \\
\hline S8-5 & 250 & 292 & 0 & 250 & 2.5 & 74.6 & 2.8 & 1.115 & 289 & 1.00 & 1.38 & 1.21 & 1.18 & 1.53 \\
\hline \multicolumn{15}{|c|}{ Frosch [21] } \\
\hline$V 1-V 2$ & 455 & 838 & 0 & 455 & 3.0 & 35 & 0.98 & 0.390 & 391 & 1.00 & 0.76 & 0.62 & 0.63 & 0.73 \\
\hline \multicolumn{15}{|c|}{ Sagaseta and Vollum [22] } \\
\hline$B G 01$ & 135 & 465 & 0 & 135 & 3.46 & 80 & 1 & 0 & 62 & 1.00 & 0.84 & 0.52 & 0.77 & 0.65 \\
\hline BLO1 & 135 & 465 & 0 & 135 & 3.46 & 68 & 1 & 0 & 50 & 1.00 & 0.72 & 0.45 & 0.80 & 0.57 \\
\hline$B G 1$ & 135 & 437 & 0 & 135 & 3.52 & 31.7 & 3.32 & 2.695 & 285 & 1.00 & 1.20 & 0.93 & 1.02 & 1.32 \\
\hline$B G 2$ & 135 & 437 & 0 & 135 & 3.52 & 31.7 & 3.32 & 4.565 & 322 & 1.00 & 0.93 & 0.70 & 0.81 & 0.99 \\
\hline$B L 1$ & 135 & 437 & 0 & 135 & 3.52 & 53.11 & 3.32 & 2.695 & 350 & 1.00 & 1.41 & 1.11 & 1.19 & 1.51 \\
\hline$B L 2$ & 135 & 437 & 0 & 135 & 3.52 & 53.11 & 3.32 & 4.565 & 478 & 1.00 & 1.32 & 1.03 & 1.17 & 1.40 \\
\hline$C B 1$ & 160 & 437 & 0 & 160 & 3.52 & 49.35 & 2.80 & 1.925 & 308 & 1.00 & 1.32 & 1.06 & 1.11 & 1.41 \\
\hline$C B 2$ & 160 & 437 & 0 & 160 & 3.52 & 49.35 & 2.80 & 2.915 & 429 & 1.00 & 1.39 & 1.11 & 1.22 & 1.49 \\
\hline \multicolumn{15}{|c|}{ Thamrin et al. [23] } \\
\hline$R-01 E$ & 125 & 219 & 0 & 125 & 3.7 & 32 & 1.0 & 0 & 33 & 1.00 & 1.28 & 0.88 & 0.93 & 1.25 \\
\hline$R-02 E$ & 125 & 219 & 0 & 125 & 3.7 & 32 & 1.5 & 0 & 37 & 1.00 & 1.35 & 0.93 & 0.95 & 1.41 \\
\hline$R-03 E$ & 125 & 212 & 0 & 125 & 3.8 & 32 & 2.5 & 0 & 38 & 1.00 & 1.32 & 0.91 & 0.89 & 1.49 \\
\hline$T-01 E$ & 125 & 219 & 70 & 250 & 3.7 & 32 & 1.0 & 0 & 37 & 1.16 & 1.24 & 0.99 & 1.04 & 1.41 \\
\hline$T-02 E$ & 125 & 219 & 70 & 250 & 3.7 & 32 & 1.5 & 0 & 39 & 1.16 & 1.23 & 0.98 & 1.00 & 1.48 \\
\hline$T-03 E$ & 125 & 212 & 70 & 250 & 3.8 & 32 & 2.5 & 0 & 48 & 1.17 & 1.43 & 1.15 & 1.12 & 1.88 \\
\hline \multicolumn{15}{|c|}{ Yoon et al. [24] } \\
\hline$N 1-S$ & 375 & 655 & 0 & 375 & 3.28 & 36 & 2.9 & 0 & 249 & 1.00 & 0.88 & 0.61 & 0.66 & 0.99 \\
\hline$N 1-N$ & 375 & 655 & 0 & 375 & 3.28 & 36 & 2.9 & 0.353 & 457 & 1.00 & 1.22 & 0.98 & 0.97 & 1.36 \\
\hline$N 2-N$ & 375 & 655 & 0 & 375 & 3.28 & 36 & 2.9 & 0.516 & 483 & 1.00 & 1.14 & 0.93 & 0.88 & 1.28 \\
\hline$M 1-S$ & 375 & 655 & 0 & 375 & 3.28 & 67 & 2.9 & 0 & 296 & 1.00 & 0.84 & 0.58 & 0.61 & 0.87 \\
\hline$M 1-N$ & 375 & 655 & 0 & 375 & 3.28 & 67 & 2.9 & 0.35 & 405 & 1.00 & 0.92 & 0.74 & 0.71 & 0.95 \\
\hline$M 2-S$ & 375 & 655 & 0 & 375 & 3.28 & 67 & 2.9 & 0.50 & 552 & 1.00 & 1.14 & 0.93 & 0.85 & 1.19 \\
\hline
\end{tabular}




\begin{tabular}{|c|c|c|c|c|c|c|c|c|c|c|c|c|c|c|}
\hline Beam label & $\begin{array}{c}b_{w} \\
(\mathrm{~mm})\end{array}$ & $\begin{array}{c}d \\
(m m)\end{array}$ & $\begin{array}{c}h_{f} \\
(\mathrm{~mm})\end{array}$ & $\begin{array}{c}b \\
(m m)\end{array}$ & $a / d$ & $\begin{array}{c}f_{c}^{\prime} \\
(M P a)\end{array}$ & $\begin{array}{l}\rho_{s l} \\
(\%)\end{array}$ & $\rho_{s t} \times f_{s t, y}$ & $V(k N)$ & $k_{f}$ & $\frac{V_{\text {exp. }}}{V_{N B B}}$ & $\frac{V_{\text {exp. }}}{V_{S B B B}}$ & $\frac{V_{\text {exp. }}}{V_{S M C F T}}$ & $\frac{V_{\text {exp. }}}{V_{A C I}}$ \\
\hline$M 2-N$ & 375 & 655 & 0 & 375 & 3.28 & 67 & 2.9 & 0.70 & 689 & 1.00 & 1.27 & 1.05 & 0.98 & 1.34 \\
\hline$H 1-S$ & 375 & 655 & 0 & 375 & 3.28 & 87 & 2.9 & 0 & 327 & 1.00 & 0.85 & 0.58 & 0.61 & 0.84 \\
\hline$H 1-N$ & 375 & 655 & 0 & 375 & 3.28 & 87 & 2.9 & 0.353 & 483 & 1.00 & 1.02 & 0.82 & 0.78 & 1.01 \\
\hline$H 2-S$ & 375 & 655 & 0 & 375 & 3.28 & 87 & 2.9 & 0.600 & 598 & 1.00 & 1.10 & 0.90 & 0.82 & 1.11 \\
\hline$H 2-N$ & 375 & 655 & 0 & 375 & 3.28 & 87 & 2.9 & 1.006 & 721 & 1.00 & 1.09 & 0.91 & 0.87 & 1.13 \\
\hline \multicolumn{15}{|c|}{ Roller and Russell [25] } \\
\hline 1 & 356 & 559 & 0 & 356 & 2.5 & 120 & 1.59 & 0.341 & 298 & 1.00 & 0.77 & 0.64 & 0.60 & 0.68 \\
\hline 2 & 356 & 559 & 0 & 356 & 2.5 & 120 & 2.89 & 1.969 & 1098 & 1.00 & 1.37 & 1.19 & 1.19 & 1.44 \\
\hline 3 & 356 & 559 & 0 & 356 & 2.5 & 120 & 4.4 & 3.939 & 1657 & 1.00 & 1.27 & 1.10 & 1.16 & 1.44 \\
\hline 4 & 356 & 559 & 0 & 356 & 2.5 & 120 & 5.78 & 5.79 & 1942 & 1.00 & 1.09 & 0.95 & 1.01 & 1.28 \\
\hline 5 & 356 & 559 & 0 & 356 & 2.5 & 120 & 6.71 & 8.11 & 2237 & 1.00 & 0.96 & 0.83 & 0.91 & 1.13 \\
\hline 6 & 457 & 762 & 0 & 457 & 3.0 & 72 & 1.65 & 0.360 & 665 & 1.00 & 1.11 & 0.92 & 0.92 & 1.06 \\
\hline 7 & 457 & 762 & 0 & 457 & 3.0 & 72 & 1.82 & 0.702 & 787 & 1.00 & 1.06 & 0.89 & 0.86 & 1.05 \\
\hline 8 & 457 & 762 & 0 & 457 & 3.0 & 125 & 1.82 & 0.363 & 484 & 1.00 & 0.69 & 0.57 & 0.55 & 0.61 \\
\hline 9 & 457 & 762 & 0 & 457 & 3.0 & 125 & 2.28 & 0.702 & 748 & 1.00 & 0.87 & 0.73 & 0.67 & 0.83 \\
\hline 10 & 457 & 762 & 0 & 457 & 3.0 & 125 & 2.75 & 1.023 & 1172 & 1.00 & 1.16 & 0.98 & 0.92 & 1.15 \\
\hline \multicolumn{15}{|c|}{ Johnson and Ramirez [26] } \\
\hline 2 & 305 & 350 & 0 & 305 & 3.13 & 36 & 2.37 & 0.334 & 222 & 1.00 & 1.34 & 1.14 & 1.06 & 1.54 \\
\hline 4 & 305 & 350 & 0 & 305 & 3.13 & 72 & 2.37 & 0.334 & 316 & 1.00 & 1.59 & 1.36 & 1.22 & 1.67 \\
\hline 5 & 305 & 350 & 0 & 305 & 3.13 & 55 & 2.37 & 0.677 & 382 & 1.00 & 1.67 & 1.45 & 1.39 & 1.85 \\
\hline \multicolumn{15}{|c|}{ Reineck et al. [27] } \\
\hline ET1 & 300 & 300 & 0 & 300 & 3.5 & 23.0 & 1.39 & 0.57 & 144.5 & 1.00 & 1.00 & 0.88 & 0.91 & 1.16 \\
\hline ET2 & 150 & 300 & 75 & 300 & 3.5 & 23.0 & 2.78 & 1.16 & 134.5 & 1.13 & 1.24 & 1.05 & 1.09 & 1.51 \\
\hline ET3 & 100 & 300 & 75 & 300 & 3.5 & 23.0 & 4.17 & 1.73 & 130.0 & 1.25 & 1.38 & 1.13 & 1.18 & 1.70 \\
\hline ET4 & 50 & 300 & 75 & 300 & 3.5 & 23.0 & 8.34 & 3.46 & 101.0 & 1.50 & 1.31 & 0.99 & 1.05 & 1.57 \\
\hline TA3 & 160 & 375 & 80 & 960 & 3.33 & 15.4 & 4.40 & 2.51 & 283 & 1.16 & 1.20 & 0.96 & 1.05 & 1.48 \\
\hline TA4 & 160 & 375 & 80 & 960 & 3.33 & 15.4 & 4.40 & 1.53 & 239 & 1.16 & 1.42 & 1.16 & 1.22 & 1.81 \\
\hline TA15 & 160 & 375 & 80 & 960 & 3.33 & 17.4 & 4.40 & 2.51 & 303 & 1.16 & 1.27 & 1.02 & 1.11 & 1.57 \\
\hline$T A 11$ & 160 & 375 & 80 & 960 & 3.33 & 24.9 & 4.40 & 2.5 & 347 & 1.16 & 1.41 & 1.15 & 1.24 & 1.73 \\
\hline TA12 & 160 & 375 & 80 & 960 & 3.33 & 24.9 & 4.40 & 1.53 & 275 & 1.16 & 1.54 & 1.28 & 1.31 & 1.93 \\
\hline TA16 & 160 & 375 & 80 & 960 & 3.33 & 17.4 & 4.40 & 2.51 & 304 & 1.16 & 1.28 & 1.03 & 1.12 & 1.57 \\
\hline$T 1$ & 152 & 254 & 76 & 610 & 3.36 & 27.9 & 1.25 & 0.58 & 109 & 1.22 & 1.63 & 1.51 & 1.56 & 1.91 \\
\hline$T 2$ & 152 & 254 & 76 & 610 & 3.36 & 28.1 & 1.46 & 0.00 & 54.7 & 1.22 & 1.20 & 1.02 & 1.06 & 1.57 \\
\hline T3 & 152 & 254 & 76 & 610 & 3.36 & 27.5 & 1.46 & 0.58 & 105 & 1.22 & 1.55 & 1.43 & 1.45 & 1.85 \\
\hline$T 4$ & 152 & 254 & 76 & 610 & 3.36 & 32.5 & 1.95 & 0.58 & 109 & 1.22 & 1.49 & 1.38 & 1.36 & 1.82 \\
\hline$T 5$ & 152 & 254 & 76 & 610 & 3.36 & 33.7 & 1.46 & 1.15 & 140 & 1.22 & 1.46 & 1.33 & 1.43 & 1.70 \\
\hline
\end{tabular}




\begin{tabular}{|c|c|c|c|c|c|c|c|c|c|c|c|c|c|c|}
\hline Beam label & $\begin{array}{c}b_{w} \\
(\mathrm{~mm})\end{array}$ & $\begin{array}{c}d \\
(m m)\end{array}$ & $\begin{array}{c}h_{f} \\
(\mathrm{~mm})\end{array}$ & $\begin{array}{c}b \\
(m m)\end{array}$ & $a / d$ & $\begin{array}{c}f_{c}^{\prime} \\
(M P a)\end{array}$ & $\begin{array}{l}\rho_{s l} \\
(\%)\end{array}$ & $\rho_{s t} \times f_{s t, y}$ & $V(k N)$ & $k_{f}$ & $\frac{V_{\text {exp. }}}{V_{N B B}}$ & $\frac{V_{\text {exp. }}}{V_{S B B B}}$ & $\frac{V_{\text {exp. }}}{V_{S M C F T}}$ & $\frac{V_{\text {exp. }}}{V_{A C I}}$ \\
\hline T6 & 152 & 254 & 76 & 610 & 3.6 & 25.8 & 4.16 & 2.25 & 205 & 1.22 & 1.33 & 1.15 & 1.22 & 1.71 \\
\hline$T 7$ & 152 & 254 & 76 & 610 & 3.46 & 27.4 & 3.00 & 0.58 & 109 & 1.22 & 1.47 & 1.34 & 1.30 & 1.92 \\
\hline$T 8$ & 152 & 254 & 76 & 610 & 3.60 & 31.3 & 4.16 & 0.58 & 125 & 1.22 & 1.56 & 1.43 & 1.35 & 2.11 \\
\hline$T 9$ & 152 & 254 & 76 & 610 & 3.60 & 20.2 & 4.16 & 1.15 & 154 & 1.22 & 1.54 & 1.36 & 1.39 & 2.08 \\
\hline$T 10$ & 152 & 254 & 76 & 610 & 3.36 & 28.2 & 1.46 & 0.38 & 87 & 1.22 & 1.46 & 1.37 & 1.35 & 1.76 \\
\hline$T 11$ & 152 & 254 & 76 & 610 & 3.60 & 37.0 & 4.16 & 1.15 & 160 & 1.22 & 1.45 & 1.32 & 1.30 & 1.90 \\
\hline$T 12$ & 152 & 254 & 76 & 610 & 3.60 & 30.7 & 4.16 & 0.58 & 145 & 1.22 & 1.82 & 1.67 & 1.58 & 2.47 \\
\hline$T 13$ & 152 & 254 & 76 & 610 & 3.36 & 12.8 & 1.46 & 0.58 & 90 & 1.22 & 1.55 & 1.39 & 1.46 & 1.96 \\
\hline$T 14$ & 152 & 254 & 76 & 610 & 3.60 & 33.4 & 4.16 & 2.25 & 219 & 1.22 & 1.38 & 1.21 & 1.27 & 1.75 \\
\hline$T 15$ & 152 & 254 & 76 & 610 & 7.20 & 33.2 & 4.16 & 0.58 & 104 & 1.22 & 1.28 & 1.18 & 1.11 & 1.73 \\
\hline$T 16$ & 152 & 254 & 76 & 610 & 7.20 & 32.7 & 4.16 & 0.38 & 93 & 1.22 & 1.30 & 1.21 & 1.11 & 1.78 \\
\hline$T 18$ & 152 & 254 & 76 & 610 & 3.60 & 28.4 & 4.16 & 0.00 & 75 & 1.22 & 1.41 & 1.20 & 1.15 & 2.14 \\
\hline$T 19$ & 152 & 254 & 76 & 610 & 5.40 & 30.0 & 4.16 & 0.58 & 113 & 1.22 & 1.43 & 1.31 & 1.24 & 1.94 \\
\hline$T 20$ & 152 & 254 & 76 & 610 & 5.40 & 32.1 & 4.16 & 1.15 & 154 & 1.22 & 1.43 & 1.29 & 1.28 & 1.89 \\
\hline$T 22$ & 152 & 254 & 76 & 610 & 3.36 & 34.4 & 1.46 & 0.58 & 109 & 1.22 & 1.53 & 1.42 & 1.43 & 1.79 \\
\hline$T 25$ & 152 & 254 & 76 & 610 & 3.36 & 54.1 & 1.46 & 0.58 & 115 & 1.22 & 1.45 & 1.37 & 1.35 & 1.63 \\
\hline$T 26$ & 152 & 254 & 76 & 610 & 3.60 & 57.0 & 4.16 & 1.15 & 179 & 1.22 & 1.51 & 1.38 & 1.33 & 1.91 \\
\hline$T 27$ & 152 & 254 & 76 & 610 & 3.60 & 12.0 & 4.16 & 1.15 & 132 & 1.22 & 1.43 & 1.23 & 1.28 & 1.97 \\
\hline T31 & 152 & 254 & 76 & 610 & 3.36 & 31.0 & 1.46 & 0.58 & 95 & 1.22 & 1.36 & 1.27 & 1.28 & 1.61 \\
\hline T32 & 152 & 254 & 76 & 610 & 3.60 & 27.6 & 4.16 & 2.25 & 216 & 1.22 & 1.39 & 1.21 & 1.28 & 1.78 \\
\hline$T 34$ & 152 & 254 & 76 & 540 & 5.40 & 43.0 & 4.16 & 0.58 & 112 & 1.22 & 1.30 & 1.20 & 1.11 & 1.71 \\
\hline T36 & 152 & 254 & 152 & 610 & 3.60 & 24.2 & 4.16 & 1.15 & 179 & 1.50 & 1.60 & 1.55 & 1.56 & 2.33 \\
\hline T37 & 152 & 254 & 76 & 610 & 3.60 & 31.8 & 4.16 & 2.25 & 210 & 1.22 & 1.33 & 1.16 & 1.22 & 1.70 \\
\hline T38 & 152 & 256 & 152 & 610 & 3.60 & 30.2 & 4.16 & 2.25 & 239 & 1.50 & 1.43 & 1.32 & 1.39 & 1.93 \\
\hline$R 1$ & 152 & 254 & 0 & 152 & 3.36 & 26.2 & 0.975 & 0.0 & 44.9 & 1.00 & 1.32 & 0.92 & 0.98 & 1.34 \\
\hline$R 2$ & 152 & 254 & 0 & 152 & 3.36 & 26.2 & 1.46 & 0.0 & 47.1 & 1.00 & 1.30 & 0.90 & 0.94 & 1.40 \\
\hline$R 3$ & 152 & 254 & 0 & 152 & 3.36 & 24.8 & 1.46 & 0.0 & 44.9 & 1.00 & 1.27 & 0.88 & 0.91 & 1.37 \\
\hline$R 7$ & 152 & 254 & 0 & 152 & 3.36 & 28.1 & 1.46 & 0.0 & 54.3 & 1.00 & 1.46 & 1.02 & 1.05 & 1.56 \\
\hline$R 8$ & 152 & 254 & 0 & 152 & 3.36 & 26.7 & 1.46 & 0.6 & 79.6 & 1.00 & 1.29 & 1.07 & 1.10 & 1.39 \\
\hline$R 9$ & 152 & 254 & 0 & 152 & 3.36 & 29.6 & 1.46 & 1.2 & 104.5 & 1.00 & 1.17 & 0.98 & 1.07 & 1.27 \\
\hline$R 10$ & 152 & 254 & 0 & 152 & 3.36 & 29.6 & 0.975 & 0.6 & 75.2 & 1.00 & 1.26 & 1.06 & 1.11 & 1.28 \\
\hline$R 11$ & 152 & 254 & 0 & 152 & 3.36 & 26.2 & 1.95 & 0.6 & 89.4 & 1.00 & 1.41 & 1.16 & 1.16 & 1.58 \\
\hline$R 12$ & 152 & 254 & 0 & 152 & 3.6 & 33.9 & 4.16 & 0.6 & 109.4 & 1.00 & 1.49 & 1.22 & 1.15 & 1.78 \\
\hline$R 13$ & 152 & 254 & 0 & 152 & 3.6 & 32.3 & 4.16 & 1.2 & 149.5 & 1.00 & 1.47 & 1.22 & 1.21 & 1.79 \\
\hline$R 14$ & 152 & 254 & 0 & 152 & 3.36 & 29.0 & 1.46 & 0.4 & 89.4 & 1.00 & 1.67 & 1.37 & 1.36 & 1.76 \\
\hline$R 15$ & 152 & 254 & 0 & 152 & 3.6 & 29.9 & 4.16 & 1.2 & 139.7 & 1.00 & 1.39 & 1.15 & 1.15 & 1.70 \\
\hline
\end{tabular}




\begin{tabular}{|c|c|c|c|c|c|c|c|c|c|c|c|c|c|c|}
\hline Beam label & $\begin{array}{c}b_{w} \\
(\mathrm{~mm})\end{array}$ & $\begin{array}{c}d \\
(m m)\end{array}$ & $\begin{array}{c}h_{f} \\
(\mathrm{~mm})\end{array}$ & $\begin{array}{c}b \\
(m m)\end{array}$ & $a / d$ & $\begin{array}{c}f_{c}^{\prime} \\
(M P a)\end{array}$ & $\begin{array}{l}\rho_{s l} \\
(\%)\end{array}$ & $\rho_{s t} \times f_{s t, y}$ & $V(k N)$ & $k_{f}$ & $\frac{V_{\text {exp. }}}{V_{N B B}}$ & $\frac{V_{\text {exp. }}}{V_{S B B B}}$ & $\frac{V_{\text {exp. }}}{V_{S M C F T}}$ & $\frac{V_{\text {exp. }}}{V_{A C I}}$ \\
\hline$R 16$ & 152 & 254 & 0 & 152 & 3.6 & 31.6 & 4.16 & 1.2 & 139.7 & 1.00 & 1.38 & 1.15 & 1.14 & 1.68 \\
\hline$R 17$ & 152 & 254 & 0 & 152 & 3.36 & 12.8 & 1.46 & 0.6 & 69.8 & 1.00 & 1.30 & 1.06 & 1.12 & 1.50 \\
\hline$R 18$ & 152 & 254 & 0 & 152 & 3.36 & 31.3 & 1.46 & 0.6 & 84.5 & 1.00 & 1.33 & 1.11 & 1.12 & 1.41 \\
\hline$R 19$ & 152 & 254 & 0 & 152 & 3.36 & 30.3 & 1.46 & 1.2 & 119.7 & 1.00 & 1.34 & 1.13 & 1.22 & 1.45 \\
\hline$R 20$ & 152 & 254 & 0 & 152 & 3.36 & 43.0 & 1.46 & 0.6 & 89.8 & 1.00 & 1.33 & 1.11 & 1.11 & 1.36 \\
\hline$R 21$ & 152 & 254 & 0 & 152 & 3.6 & 48.0 & 4.16 & 1.2 & 149.5 & 1.00 & 1.39 & 1.16 & 1.13 & 1.63 \\
\hline$R 22$ & 152 & 254 & 0 & 152 & 4.5 & 29.5 & 1.46 & 0.6 & 79.6 & 1.00 & 1.27 & 1.06 & 1.07 & 1.35 \\
\hline$R 24$ & 152 & 254 & 0 & 152 & 5.05 & 30.9 & 4.16 & 0.6 & 92.1 & 1.00 & 1.28 & 1.05 & 0.99 & 1.54 \\
\hline$R 25$ & 152 & 254 & 0 & 152 & 3.6 & 30.8 & 4.16 & 0.6 & 104.5 & 1.00 & 1.46 & 1.19 & 1.12 & 1.75 \\
\hline$R 27$ & 152 & 254 & 0 & 152 & 3.6 & 13.7 & 4.16 & 1.2 & 94.7 & 1.00 & 1.04 & 0.85 & 0.88 & 1.34 \\
\hline$R 28$ & 152 & 254 & 0 & 152 & 3.6 & 31.6 & 4.16 & 2.2 & 179.3 & 1.00 & 1.21 & 1.01 & 1.06 & 1.47 \\
\hline$T 21$ & 110 & 298 & 80 & 400 & 3.5 & 33.1 & 3.84 & 1.42 & 132 & 1.29 & 1.35 & 1.16 & 1.18 & 1.68 \\
\hline$T 22$ & 110 & 298 & 80 & 400 & 3.5 & 31.7 & 3.84 & 1.51 & 130 & 1.29 & 1.29 & 1.11 & 1.13 & 1.61 \\
\hline$T 23$ & 110 & 298 & 80 & 400 & 3.5 & 35 & 3.84 & 1.20 & 142 & 1.29 & 1.57 & 1.37 & 1.36 & 1.96 \\
\hline$T 1 a$ & 110 & 298 & 80 & 400 & 3.5 & 23.4 & 3.84 & 1.53 & 135 & 1.29 & 1.39 & 1.18 & 1.22 & 1.75 \\
\hline$T 2 a$ & 110 & 298 & 80 & 400 & 3.5 & 25.1 & 3.84 & 1.64 & 139 & 1.29 & 1.36 & 1.15 & 1.20 & 1.70 \\
\hline Ta3 & 110 & 298 & 80 & 400 & 3.5 & 25.1 & 3.84 & 1.32 & 130 & 1.29 & 1.44 & 1.23 & 1.26 & 1.83 \\
\hline Ta4 & 110 & 298 & 80 & 400 & 3.5 & 25.7 & 3.84 & 1.37 & 135 & 1.29 & 1.46 & 1.25 & 1.28 & 1.85 \\
\hline$T 1 b$ & 110 & 298 & 80 & 400 & 3.5 & 23.6 & 3.84 & 1.15 & 120 & 1.29 & 1.45 & 1.24 & 1.26 & 1.85 \\
\hline$T 2 b$ & 110 & 298 & 80 & 400 & 3.5 & 25.4 & 3.84 & 1.23 & 132 & 1.29 & 1.52 & 1.30 & 1.32 & 1.93 \\
\hline$T 3 b$ & 110 & 298 & 80 & 400 & 3.5 & 25.1 & 3.84 & 0.77 & 118 & 1.29 & 1.70 & 1.49 & 1.46 & 2.22 \\
\hline$T 4 b$ & 110 & 298 & 80 & 400 & 3.5 & 25.2 & 3.84 & 0.82 & 109 & 1.29 & 1.53 & 1.34 & 1.31 & 1.99 \\
\hline$T 5$ & 110 & 298 & 80 & 400 & 3.5 & 26 & 3.84 & 0.82 & 112 & 1.29 & 1.56 & 1.37 & 1.34 & 2.03 \\
\hline$P 5$ & 150 & 285 & 80 & 600 & 3.5 & 43.0 & 1.45 & 1.07 & 145 & 1.22 & 1.38 & 1.26 & 1.32 & 1.55 \\
\hline$P 20$ & 150 & 285 & 80 & 600 & 3.5 & 40.7 & 1.94 & 0.65 & 120 & 1.22 & 1.38 & 1.26 & 1.24 & 1.62 \\
\hline$P 23$ & 150 & 285 & 80 & 600 & 3.5 & 43.1 & 1.94 & 1.07 & 160 & 1.22 & 1.47 & 1.33 & 1.37 & 1.71 \\
\hline No. 2 & 190 & 374 & 102 & 610 & 4.14 & 32.8 & 0.69 & 0.00 & 72 & 1.22 & 0.94 & 0.78 & 0.79 & 1.04 \\
\hline$A 00$ & 190 & 394 & 102 & 610 & 3.92 & 32.7 & 0.66 & 0.00 & 65 & 1.21 & 0.83 & 0.67 & 0.65 & 0.89 \\
\hline$A 25$ & 190 & 390 & 102 & 610 & 3.97 & 32.6 & 0.66 & 0.22 & 86 & 1.21 & 0.95 & 0.88 & 0.88 & 0.97 \\
\hline$A 25 a$ & 190 & 388 & 102 & 610 & 4.00 & 33.1 & 0.67 & 0.22 & 83 & 1.21 & 0.91 & 0.85 & 0.84 & 0.94 \\
\hline$A 50$ & 190 & 392 & 102 & 610 & 3.96 & 26.3 & 0.66 & 0.51 & 115 & 1.21 & 1.07 & 0.97 & 1.05 & 1.12 \\
\hline$A 50 a$ & 190 & 393 & 102 & 610 & 3.94 & 28.0 & 0.66 & 0.51 & 109 & 1.21 & 1.00 & 0.90 & 0.98 & 1.04 \\
\hline$A 75$ & 190 & 395 & 102 & 610 & 3.92 & 32.2 & 0.66 & 0.67 & 142 & 1.21 & 1.13 & 1.02 & 1.15 & 1.16 \\
\hline No. 1 & 190 & 371 & 102 & 610 & 4.18 & 38.1 & 0.70 & 0.76 & 134 & 1.22 & 1.02 & 0.94 & 1.08 & 1.05 \\
\hline$B 00$ & 190 & 399 & 102 & 610 & 3.88 & 32.0 & 0.49 & 0.00 & 70 & 1.21 & 0.93 & 0.75 & 1.49 & 0.96 \\
\hline$B 25$ & 190 & 394 & 102 & 610 & 3.93 & 30.8 & 0.49 & 0.22 & 79 & 1.21 & 0.92 & 0.85 & 0.90 & 0.91 \\
\hline
\end{tabular}




\begin{tabular}{|c|c|c|c|c|c|c|c|c|c|c|c|c|c|c|}
\hline Beam label & $\begin{array}{c}b_{w} \\
(\mathrm{~mm})\end{array}$ & $\begin{array}{c}d \\
(m m)\end{array}$ & $\begin{array}{c}h_{f} \\
(\mathrm{~mm})\end{array}$ & $\begin{array}{c}b \\
(m m)\end{array}$ & $a / d$ & $\begin{array}{c}f_{c}^{\prime} \\
(M P a)\end{array}$ & $\begin{array}{l}\rho_{s l} \\
(\%)\end{array}$ & $\rho_{s t} \times f_{s t, y}$ & $V(k N)$ & $k_{f}$ & $\frac{V_{\text {exp. }}}{V_{N B B}}$ & $\frac{V_{\text {exp. }}}{V_{S B B B}}$ & $\frac{V_{\text {exp. }}}{V_{S M C F T}}$ & $\frac{V_{\text {exp. }}}{V_{A C I}}$ \\
\hline$B 50$ & 190 & 391 & 102 & 610 & 3.96 & 30.6 & 0.50 & 0.53 & 107 & 1.21 & 0.99 & 0.90 & 1.28 & 0.98 \\
\hline$C 50$ & 190 & 393 & 102 & 610 & 3.94 & 29.7 & 0.94 & 0.53 & 134 & 1.21 & 1.14 & 1.03 & 1.07 & 1.23 \\
\hline$C 75$ & 190 & 395 & 102 & 610 & 3.92 & 29.4 & 0.93 & 0.71 & 138 & 1.21 & 1.04 & 0.93 & 1.00 & 1.13 \\
\hline$I$ & 50 & 240 & 65 & 200 & 10.4 & 40 & 5.23 & 0.00 & 22 & 1.41 & 1.16 & 0.97 & 0.90 & 1.71 \\
\hline$I I I$ & 50 & 240 & 65 & 200 & 3.33 & 40 & 5.23 & 0.00 & 37 & 1.41 & 1.95 & 1.63 & 1.51 & 2.87 \\
\hline$V H A$ & 75 & 704 & 140 & 585 & 3.41 & 44.5 & 14.5 & 8.87 & 887 & 1.50 & 1.58 & 1.07 & 1.16 & 1.68 \\
\hline$H A-45$ & 150 & 1369 & 280 & 1450 & 3.06 & 43.3 & 9.4 & 9.75 & 3384 & 1.50 & 1.57 & 1.00 & 1.14 & 1.52 \\
\hline$R C 30 \mathrm{Al}$ & 120 & 940 & 130 & 900 & 4.04 & 25 & 8.02 & 4.02 & 682 & 1.22 & 1.13 & 0.79 & 0.85 & 1.24 \\
\hline$R C 60 \mathrm{Al}$ & 120 & 940 & 130 & 900 & 4.04 & 47 & 9.41 & 4.02 & 938 & 1.22 & 1.43 & 1.05 & 1.09 & 1.60 \\
\hline$R C 60 \mathrm{Bl}$ & 120 & 940 & 130 & 900 & 4.04 & 50 & 12.53 & 6.03 & 1200 & 1.22 & 1.31 & 0.95 & 1.00 & 1.47 \\
\hline$R C 70 \mathrm{~B} 1$ & 120 & 940 & 130 & 900 & 4.04 & 60 & 12.53 & 6.03 & 1330 & 1.22 & 1.43 & 1.05 & 1.09 & 1.60 \\
\hline 2 & 90 & 647 & 125 & 500 & 2.56 & 87.4 & 6.13 & 4.06 & 548 & 1.40 & 1.53 & 1.20 & 1.24 & 1.67 \\
\hline 3 & 90 & 647 & 125 & 500 & 2.56 & 88.3 & 8.98 & 9.60 & 891 & 1.40 & 1.30 & 0.95 & 1.05 & 1.37 \\
\hline 4 & 90 & 661 & 125 & 500 & 2.50 & 89.3 & 10.81 & 16.67 & 1221 & 1.39 & 1.17 & 0.78 & 0.91 & 1.12 \\
\hline$I B-2 R$ & 178 & 308 & 102 & 584 & 2.97 & 16.8 & 1.42 & 1.29 & 140 & 1.28 & 1.07 & 0.94 & 1.05 & 1.29 \\
\hline$I C-I R$ & 178 & 299 & 102 & 584 & 3.06 & 34.0 & 4.53 & 5.46 & 414 & 1.29 & 1.00 & 0.83 & 0.96 & 1.21 \\
\hline$I C-2 R$ & 178 & 310 & 102 & 584 & 2.95 & 34.0 & 4.37 & 1.29 & 227 & 1.28 & 1.35 & 1.23 & 1.23 & 1.80 \\
\hline$I D-2 R$ & 178 & 306 & 102 & 584 & 2.99 & 34.0 & 2.47 & 1.29 & 220 & 1.29 & 1.42 & 1.30 & 1.35 & 1.77 \\
\hline$G T-2$ & 120 & 350 & 100 & 500 & 3.46 & 24.9 & 2.99 & 1.21 & 148 & 1.36 & 1.37 & 1.19 & 1.23 & 1.71 \\
\hline$G T-4$ & 120 & 350 & 100 & 500 & 3.46 & 31.0 & 2.99 & 2.51 & 227 & 1.36 & 1.33 & 1.11 & 1.22 & 1.56 \\
\hline$G T-5$ & 120 & 350 & 100 & 500 & 3.46 & 19.5 & 2.99 & 3.22 & 222 & 1.36 & 1.16 & 0.91 & 1.06 & 1.33 \\
\hline$A 2$ & 155 & 719 & 150 & 655 & 2.68 & 30.8 & 2.86 & 2.62 & 657 & 1.30 & 1.52 & 1.18 & 1.30 & 1.65 \\
\hline$B 2$ & 155 & 719 & 150 & 655 & 2.68 & 31.4 & 2.86 & 1.96 & 571 & 1.30 & 1.58 & 1.26 & 1.34 & 1.76 \\
\hline Stb III & 77 & 590 & 107 & 838 & 4.27 & 60.6 & 13.55 & 6.16 & 537 & 1.38 & 1.37 & 1.02 & 1.07 & 1.58 \\
\hline$S t b I$ & 77 & 590 & 100 & 837 & 4.27 & 60.6 & 15.61 & 9.21 & 682 & 1.33 & 1.29 & 0.92 & 0.98 & 1.43 \\
\hline $5 A-0$ & 120 & 540 & 90 & 700 & 2.78 & 25.7 & 3.88 & 3.53 & 435 & 1.19 & 1.40 & 1.04 & 1.17 & 1.53 \\
\hline $5 B-0$ & 120 & 540 & 90 & 700 & 2.78 & 26.6 & 3.88 & 3.39 & 435 & 1.19 & 1.44 & 1.08 & 1.20 & 1.57 \\
\hline DB0.530M & 300 & 925 & 0 & 300 & 2.88 & 32 & 0.5 & 0.4 & 265 & 1.00 & 0.84 & 0.65 & 0.83 & 0.70 \\
\hline$B 1 S$ & 240 & 300 & 0 & 300 & 2.70 & 27.2 & 1.26 & 0.65 & 129 & 1.00 & 1.06 & 0.92 & 0.96 & 1.17 \\
\hline$B 2 S$ & 240 & 600 & 0 & 600 & 2.80 & 25.5 & 1.26 & 0.65 & 250 & 1.00 & 1.13 & 0.90 & 0.94 & 1.15 \\
\hline$B 3 S$ & 240 & 900 & 0 & 900 & 2.85 & 26.7 & 1.26 & 0.65 & 369 & 1.00 & 1.17 & 0.88 & 0.91 & 1.12 \\
\hline$B 4 S$ & 240 & 1200 & 0 & 1200 & 2.88 & 25.8 & 1.26 & 0.65 & 473 & 1.00 & 1.17 & 0.85 & 0.89 & 1.09 \\
\hline$V 1$ & 175 & 322 & 0 & 175 & 3.57 & 38 & 1.07 & 0.70 & 100 & 1.00 & 1.02 & 0.85 & 0.89 & 1.02 \\
\hline$V L 1$ & 120 & 278 & 63 & 301 & 3.24 & 43 & 3.01 & 3.07 & 190 & 1.17 & 1.19 & 0.99 & 1.10 & 1.36 \\
\hline $\begin{array}{c}R s I S / B Q I I \\
0\end{array}$ & 250 & 430 & 125 & 900 & 3.0 & 24.5 & 3.95 & 4.26 & 595 & 1.22 & 0.90 & 0.74 & 0.85 & 1.08 \\
\hline
\end{tabular}




\begin{tabular}{|c|c|c|c|c|c|c|c|c|c|c|c|c|c|c|}
\hline Beam label & $\begin{array}{c}b_{w} \\
(m m)\end{array}$ & $\begin{array}{c}d \\
(m m)\end{array}$ & $\begin{array}{c}h_{f} \\
(\mathrm{~mm})\end{array}$ & $\begin{array}{c}b \\
(\mathrm{~mm})\end{array}$ & $a / d$ & $\begin{array}{c}f_{c}^{\prime} \\
(M P a)\end{array}$ & $\begin{array}{l}\rho_{s l} \\
(\%)\end{array}$ & $\rho_{s t} \times f_{s t, y}$ & $V(k N)$ & $k_{f}$ & $\frac{V_{\text {exp. }}}{V_{N B B}}$ & $\frac{V_{\text {exp. }}}{V_{S B B B}}$ & $\frac{V_{\text {exp. }}}{V_{S M C F T}}$ & $\frac{V_{\text {exp. }}}{V_{A C I}}$ \\
\hline RnIIS & 450 & 548 & 150 & 950 & 3.0 & 22.1 & 1.36 & 1.87 & 745 & 1.14 & 0.96 & 0.85 & 0.99 & 1.13 \\
\hline \multicolumn{15}{|c|}{ Hsiung and Frantz [28] } \\
\hline$A$ & 152 & 419 & 0 & 152 & 3 & 43 & 1.82 & 0.62 & 110 & 1.00 & 1.01 & 0.79 & 0.77 & 1.00 \\
\hline$B$ & 305 & 419 & 0 & 305 & 3 & 43 & 1.82 & 0.62 & 200 & 1.00 & 0.84 & 0.71 & 0.70 & 0.90 \\
\hline$C$ & 457 & 419 & 0 & 457 & 3 & 43 & 1.82 & 0.62 & 339 & 1.00 & 0.90 & 0.81 & 0.79 & 1.02 \\
\hline \multicolumn{15}{|c|}{ Mphonde [29] } \\
\hline$B 50-3-3$ & 153 & 299 & 0 & 153 & 3.6 & 22 & 3.36 & 0.34 & 76 & 1.00 & 1.23 & 0.97 & 0.92 & 1.46 \\
\hline B50-7-3 & 153 & 299 & 0 & 153 & 3.6 & 40 & 3.36 & 0.34 & 94 & 1.00 & 1.32 & 1.04 & 0.92 & 1.45 \\
\hline B50-11-3 & 153 & 299 & 0 & 153 & 3.6 & 60 & 3.36 & 0.34 & 98 & 1.00 & 1.23 & 0.98 & 0.85 & 1.29 \\
\hline B50-115-3 & 153 & 299 & 0 & 153 & 3.6 & 83 & 3.36 & 0.34 & 111 & 1.00 & 1.28 & 1.01 & 0.87 & 1.28 \\
\hline B100-3-3 & 153 & 299 & 0 & 153 & 3.6 & 28 & 3.36 & 0.69 & 95 & 1.00 & 1.12 & 0.90 & 0.88 & 1.31 \\
\hline B100-7-3 & 153 & 299 & 0 & 153 & 3.6 & 59 & 3.36 & 0.69 & 94 & 1.00 & 0.96 & 0.78 & 0.72 & 1.03 \\
\hline B100-11-1 & 153 & 299 & 0 & 153 & 3.6 & 69 & 3.36 & 0.69 & 152 & 1.00 & 1.50 & 1.22 & 1.12 & 1.58 \\
\hline B100-15-3 & 153 & 299 & 0 & 153 & 3.6 & 82 & 3.36 & 0.69 & 116 & 1.00 & 1.10 & 0.89 & 0.82 & 1.14 \\
\hline B150-3-3 & 153 & 299 & 0 & 153 & 3.6 & 29 & 3.36 & 1.03 & 139 & 1.00 & 1.33 & 1.08 & 1.09 & 1.56 \\
\hline B150-7-3 & 153 & 299 & 0 & 153 & 3.6 & 47 & 3.36 & 1.03 & 133 & 1.00 & 1.18 & 0.97 & 0.95 & 1.32 \\
\hline B150-11-3 & 153 & 299 & 0 & 153 & 3.6 & 70 & 3.36 & 1.03 & 161 & 1.00 & 1.34 & 1.10 & 1.05 & 1.44 \\
\hline B150-15-3 & 153 & 299 & 0 & 153 & 3.6 & 83 & 3.36 & 1.03 & 150 & 1.00 & 1.21 & 1.00 & 0.94 & 1.27 \\
\hline \multicolumn{15}{|c|}{ Sarsam and Al-Musawi [30] } \\
\hline$A L 2-N$ & 180 & 235 & 0 & 180 & 4 & 10 & 2.23 & 0.76 & 115 & 1.00 & 1.65 & 1.38 & 1.44 & 2.10 \\
\hline$A L 2-H$ & 180 & 235 & 0 & 180 & 4 & 75 & 2.23 & 0.76 & 123 & 1.00 & 1.24 & 1.07 & 1.03 & 1.30 \\
\hline$A S 2-H$ & 180 & 232 & 0 & 180 & 2.5 & 76 & 2.26 & 0.76 & 201 & 1.00 & 2.04 & 1.77 & 1.65 & 2.15 \\
\hline$A S 3-N$ & 180 & 235 & 0 & 180 & 2.5 & 40 & 2.23 & 1.14 & 199 & 1.00 & 1.86 & 1.61 & 1.47 & 2.12 \\
\hline$A S 3-H$ & 180 & 235 & 0 & 180 & 2.5 & 72 & 2.23 & 1.14 & 199 & 1.00 & 1.70 & 1.48 & 1.10 & 1.82 \\
\hline BL2-H & 180 & 233 & 0 & 180 & 4 & 76 & 2.82 & 0.76 & 138 & 1.00 & 1.36 & 1.17 & 1.61 & 1.47 \\
\hline$B S 3-H$ & 180 & 233 & 0 & 180 & 2.5 & 73 & 2.82 & 1.14 & 228 & 1.00 & 1.90 & 1.65 & 1.28 & 2.10 \\
\hline BS4-H & 180 & 233 & 0 & 180 & 2.5 & 80 & 2.82 & 1.53 & 207 & 1.00 & 1.46 & 1.28 & 1.14 & 1.62 \\
\hline CL2-H & 180 & 233 & 0 & 180 & 4 & 70 & 3.51 & 0.76 & 147 & 1.00 & 1.44 & 1.23 & 1.31 & 1.61 \\
\hline CS3-H & 180 & 233 & 0 & 180 & 2.5 & 74 & 3.51 & 1.14 & 247 & 1.00 & 2.00 & 1.73 & 1.44 & 2.26 \\
\hline CS4-H & 180 & 233 & 0 & 180 & 2.5 & 76 & 3.51 & 1.53 & 220 & 1.00 & 1.53 & 1.33 & 1.03 & 1.74 \\
\hline \multicolumn{15}{|c|}{ Ozcebe et al. [31] } \\
\hline ACI56 & 150 & 310 & 0 & 150 & 5 & 58 & 3.46 & 0.31 & 94 & 1.00 & 1.20 & 0.94 & 0.82 & 1.26 \\
\hline TH56 & 150 & 310 & 0 & 150 & 5 & 63 & 3.46 & 0.38 & 103 & 1.00 & 1.23 & 0.97 & 0.85 & 1.28 \\
\hline TS56 & 150 & 310 & 0 & 150 & 5 & 61 & 3.46 & 0.54 & 129 & 1.00 & 1.40 & 1.12 & 1.02 & 1.49 \\
\hline ACI59 & 150 & 310 & 0 & 150 & 5 & 82 & 4.43 & 0.31 & 97 & 1.00 & 1.09 & 0.85 & 0.71 & 1.13 \\
\hline TH59 & 150 & 310 & 0 & 150 & 5 & 75 & 4.43 & 0.42 & 119 & 1.00 & 1.28 & 1.01 & 0.86 & 1.35 \\
\hline
\end{tabular}




\begin{tabular}{|c|c|c|c|c|c|c|c|c|c|c|c|c|c|c|}
\hline Beam label & $\begin{array}{c}b_{w} \\
(m m)\end{array}$ & $\begin{array}{c}d \\
(m m)\end{array}$ & $\begin{array}{c}h_{f} \\
(m m)\end{array}$ & $\begin{array}{c}b \\
(m m)\end{array}$ & $a / d$ & $\begin{array}{c}f_{c}^{\prime} \\
(M P a)\end{array}$ & $\begin{array}{c}\rho_{s l} \\
(\%)\end{array}$ & $\rho_{s t} \times f_{s t, y}$ & $V(k N)$ & $k_{f}$ & $\frac{V_{\text {exp. }}}{V_{N B B}}$ & $\frac{V_{\text {exp. }}}{V_{S B B B}}$ & $\frac{V_{\text {exp. }}}{V_{S M C F T}}$ & $\frac{V_{\text {exp. }}}{V_{A C I}}$ \\
\hline TS59 & 150 & 310 & 0 & 150 & 5 & 82 & 4.43 & 0.63 & 125 & 1.00 & 1.17 & 0.94 & 0.84 & 1.24 \\
\hline ACI36 & 150 & 310 & 0 & 150 & 3 & 75 & 2.59 & 0.31 & 105 & 1.00 & 1.30 & 1.03 & 0.90 & 1.27 \\
\hline TH36 & 150 & 310 & 0 & 150 & 3 & 75 & 2.59 & 0.38 & 141 & 1.00 & 1.67 & 1.33 & 1.17 & 1.64 \\
\hline TS36 & 150 & 310 & 0 & 150 & 3 & 75 & 2.59 & 0.54 & 156 & 1.00 & 1.68 & 1.35 & 1.24 & 1.67 \\
\hline ACI39 & 150 & 310 & 0 & 150 & 3 & 73 & 3.07 & 0.31 & 112 & 1.00 & 1.37 & 1.07 & 0.93 & 1.37 \\
\hline TH39 & 150 & 310 & 0 & 150 & 3 & 73 & 3.07 & 0.38 & 143 & 1.00 & 1.67 & 1.32 & 1.15 & 1.68 \\
\hline TS39 & 150 & 310 & 0 & 150 & 3 & 73 & 3.07 & 0.63 & 179 & 1.00 & 1.80 & 1.45 & 1.34 & 1.85 \\
\hline \multicolumn{15}{|c|}{ Angelakos et al. [32] } \\
\hline$D B 120$ & 300 & 925 & 0 & 300 & 2.92 & 21 & 1.01 & 0 & 179 & 1.00 & 0.86 & 0.55 & 0.67 & 0.83 \\
\hline$D B 130$ & 300 & 925 & 0 & 300 & 2.92 & 32 & 1.01 & 0 & 185 & 1.00 & 0.77 & 0.49 & 0.59 & 0.69 \\
\hline$D B 140$ & 300 & 925 & 0 & 300 & 2.92 & 38 & 1.01 & 0 & 180 & 1.00 & 0.70 & 0.45 & 0.53 & 0.62 \\
\hline$D B 165$ & 300 & 925 & 0 & 300 & 2.92 & 65 & 1.01 & 0 & 185 & 1.00 & 0.60 & 0.38 & 0.44 & 0.49 \\
\hline DB180 & 300 & 925 & 0 & 300 & 2.92 & 80 & 1.01 & 0 & 172 & 1.00 & 0.52 & 0.33 & 0.36 & 0.41 \\
\hline$D B 230$ & 300 & 895 & 0 & 300 & 3 & 32 & 2.09 & 0 & 257 & 1.00 & 0.98 & 0.63 & 0.73 & 1.00 \\
\hline$D B 0.530$ & 300 & 925 & 0 & 300 & 2.92 & 32 & 0.5 & 0 & 165 & 1.00 & 0.76 & 0.48 & 0.36 & 0.62 \\
\hline DB0.530M & 300 & 925 & 0 & 300 & 2.92 & 32 & 0.5 & 0.40 & 263 & 1.00 & 0.84 & 0.65 & 0.83 & 0.70 \\
\hline$D B 120 M$ & 300 & 925 & 0 & 300 & 2.92 & 21 & 1.01 & 0.40 & 282 & 1.00 & 0.89 & 0.68 & 0.70 & 0.86 \\
\hline DB140M & 300 & 925 & 0 & 300 & 2.92 & 38 & 1.01 & 0.40 & 277 & 1.00 & 0.77 & 0.59 & 0.59 & 0.69 \\
\hline$D B 165 M$ & 300 & 925 & 0 & 300 & 2.92 & 65 & 1.01 & 0.40 & 452 & 1.00 & 1.10 & 0.85 & 0.91 & 0.92 \\
\hline DB180M & 300 & 925 & 0 & 300 & 2.92 & 80 & 1.01 & 0.40 & 395 & 1.00 & 0.91 & 0.70 & 0.74 & 0.74 \\
\hline$B 100$ & 300 & 895 & 0 & 300 & 3 & 36 & 1.01 & 0 & 225 & 1.00 & 0.92 & 0.59 & 0.70 & 0.82 \\
\hline B100HE & 300 & 925 & 0 & 300 & 2.92 & 98 & 1.01 & 0 & 217 & 1.00 & 0.61 & 0.39 & 0.39 & 0.46 \\
\hline B100L & 300 & 925 & 0 & 300 & 2.92 & 39 & 1.01 & 0 & 223 & 1.00 & 0.86 & 0.55 & 0.65 & 0.76 \\
\hline BN100 & 300 & 925 & 0 & 300 & 2.92 & 37 & 0.76 & 0 & 192 & 1.00 & 0.79 & 0.50 & 0.60 & 0.67 \\
\hline BH100 & 300 & 925 & 0 & 300 & 2.92 & 99 & 0.76 & 0 & 193 & 1.00 & 0.56 & 0.36 & 0.19 & 0.41 \\
\hline BRL100 & 300 & 925 & 0 & 300 & 2.92 & 94 & 0.5 & 0 & 163 & 1.00 & 0.52 & 0.33 & 0.20 & 0.36 \\
\hline$B M 100$ & 300 & 925 & 0 & 300 & 2.92 & 47 & 0.76 & 0.40 & 342 & 1.00 & 0.94 & 0.73 & 0.80 & 0.79 \\
\hline \multicolumn{15}{|c|}{ Bresler and Scordelis [33] } \\
\hline$O A-1$ & 310 & 461 & 0 & 310 & 3.97 & 27 & 1.81 & 0.00 & 167 & 1.00 & 1.17 & 0.83 & 0.89 & 1.32 \\
\hline$O A-2$ & 305 & 466 & 0 & 305 & 4.9 & 34 & 2.27 & 0.00 & 178 & 1.00 & 1.13 & 0.79 & 0.83 & 1.26 \\
\hline$O A-3$ & 307 & 462 & 0 & 307 & 6.94 & 48 & 2.74 & 0.00 & 189 & 1.00 & 1.03 & 0.73 & 0.74 & 1.13 \\
\hline$A-1$ & 307 & 466 & 0 & 307 & 3.92 & 27 & 1.8 & 0.33 & 234 & 1.00 & 1.22 & 1.01 & 0.97 & 1.35 \\
\hline$A-2$ & 305 & 464 & 0 & 305 & 4.93 & 34 & 2.28 & 0.33 & 245 & 1.00 & 1.19 & 0.97 & 0.93 & 1.31 \\
\hline$B-1$ & 231 & 461 & 0 & 231 & 3.95 & 27 & 2.43 & 0.48 & 222 & 1.00 & 1.37 & 1.10 & 1.06 & 1.53 \\
\hline$B-2$ & 229 & 466 & 0 & 229 & 4.91 & 34 & 2.43 & 0.48 & 200 & 1.00 & 1.18 & 0.94 & 0.90 & 1.27 \\
\hline$C-1$ & 155 & 464 & 0 & 155 & 3.95 & 27 & 1.8 & 0.65 & 156 & 1.00 & 1.37 & 1.06 & 1.07 & 1.41 \\
\hline
\end{tabular}




\begin{tabular}{|c|c|c|c|c|c|c|c|c|c|c|c|c|c|c|}
\hline Beam label & $\begin{array}{c}b_{w} \\
(m m)\end{array}$ & $\begin{array}{c}d \\
(m m)\end{array}$ & $\begin{array}{c}h_{f} \\
(m m)\end{array}$ & $\begin{array}{c}b \\
(m m)\end{array}$ & $a / d$ & $\begin{array}{c}f_{c}^{\prime} \\
(M P a)\end{array}$ & $\begin{array}{c}\rho_{s l} \\
(\%)\end{array}$ & $\rho_{s t} \times f_{s t, y}$ & $V(k N)$ & $k_{f}$ & $\frac{V_{\text {exp. }}}{V_{N B B}}$ & $\frac{V_{\text {exp. }}}{V_{S B B B}}$ & $\frac{V_{\text {exp. }}}{V_{S M C F T}}$ & $\frac{V_{\text {exp. }}}{V_{A C I}}$ \\
\hline$C-2$ & 152 & 464 & 0 & 152 & 4.93 & 34 & 3.66 & 0.66 & 162 & 1.00 & 1.27 & 0.97 & 0.92 & 1.39 \\
\hline \multicolumn{15}{|c|}{ Lee et al. [34] } \\
\hline$S 20-1$ & 250 & 300 & 0 & 250 & 2.5 & 25 & 2.7 & 1.45 & 187 & 1.00 & 0.89 & 0.76 & 0.80 & 1.08 \\
\hline$S 20-2$ & 250 & 300 & 0 & 250 & 2.5 & 25 & 2.7 & 1.67 & 201 & 1.00 & 0.87 & 0.75 & 0.80 & 1.06 \\
\hline$S 20-3$ & 250 & 300 & 0 & 250 & 2.5 & 25 & 2.7 & 1.90 & 221 & 1.00 & 0.88 & 0.75 & 0.82 & 1.07 \\
\hline S20-4 & 250 & 300 & 0 & 250 & 2.5 & 25 & 2.7 & 2.25 & 252 & 1.00 & 0.89 & 0.76 & 0.84 & 1.08 \\
\hline S30-1 & 300 & 520 & 0 & 300 & 4 & 33 & 2.92 & 0.00 & 190 & 1.00 & 1.09 & 0.75 & 0.79 & 1.25 \\
\hline$S 30-3$ & 300 & 520 & 0 & 300 & 4 & 33 & 2.92 & 0.87 & 300 & 1.00 & 0.90 & 0.75 & 0.74 & 1.04 \\
\hline S30-4 & 300 & 520 & 0 & 300 & 4 & 33 & 2.92 & 0.87 & 311 & 1.00 & 0.94 & 0.77 & 0.76 & 1.08 \\
\hline S30-5 & 300 & 520 & 0 & 300 & 4 & 33 & 2.92 & 1.74 & 447 & 1.00 & 0.90 & 0.75 & 0.79 & 1.05 \\
\hline$S 35-1$ & 250 & 300 & 0 & 250 & 2.5 & 35 & 2.7 & 1.45 & 226 & 1.00 & 1.03 & 0.89 & 0.93 & 1.23 \\
\hline S35-2 & 250 & 300 & 0 & 250 & 2.5 & 35 & 2.7 & 1.67 & 245 & 1.00 & 1.02 & 0.89 & 0.93 & 1.22 \\
\hline S35-3 & 250 & 300 & 0 & 250 & 2.5 & 35 & 2.7 & 1.90 & 258 & 1.00 & 0.99 & 0.86 & 0.92 & 1.18 \\
\hline S35-4 & 250 & 300 & 0 & 250 & 2.5 & 35 & 2.7 & 2.25 & 254 & 1.00 & 0.87 & 0.75 & 0.82 & 1.04 \\
\hline $540-1$ & 300 & 369 & 0 & 300 & 2.76 & 38 & 4.65 & 0.00 & 176 & 1.00 & 1.20 & 0.87 & 0.85 & 1.52 \\
\hline$S 40-2$ & 300 & 369 & 0 & 300 & 2.76 & 38 & 4.65 & 1.89 & 398 & 1.00 & 0.97 & 0.84 & 0.86 & 1.22 \\
\hline$S 40-3$ & 300 & 369 & 0 & 300 & 2.76 & 38 & 4.65 & 2.42 & 537 & 1.00 & 1.11 & 0.96 & 1.00 & 1.40 \\
\hline $540-4$ & 300 & 369 & 0 & 300 & 2.76 & 38 & 4.65 & 2.78 & 567 & 1.00 & 1.07 & 0.92 & 0.97 & 1.34 \\
\hline$S 40-5$ & 300 & 369 & 0 & 300 & 2.76 & 38 & 4.65 & 3.17 & 592 & 1.00 & 1.01 & 0.87 & 0.94 & 1.27 \\
\hline $540-6$ & 300 & 369 & 0 & 300 & 2.76 & 38 & 4.65 & 3.75 & 491 & 1.00 & 0.74 & 0.64 & 0.70 & 0.92 \\
\hline $550-1$ & 300 & 369 & 0 & 300 & 2.76 & 50 & 4.65 & 0.00 & 187 & 1.00 & 1.15 & 0.84 & 0.81 & 1.41 \\
\hline S50-2 & 300 & 369 & 0 & 300 & 2.76 & 50 & 4.65 & 1.89 & 587 & 1.00 & 1.39 & 1.21 & 1.22 & 1.71 \\
\hline $550-3$ & 300 & 369 & 0 & 300 & 2.76 & 50 & 4.65 & 2.42 & 641 & 1.00 & 1.30 & 1.13 & 1.16 & 1.60 \\
\hline S50-4 & 300 & 369 & 0 & 300 & 2.76 & 50 & 4.65 & 2.78 & 657 & 1.00 & 1.21 & 1.05 & 1.10 & 1.49 \\
\hline$S 50-5$ & 300 & 369 & 0 & 300 & 2.76 & 50 & 4.65 & 3.17 & 710 & 1.00 & 1.19 & 1.03 & 1.10 & 1.47 \\
\hline $550-6$ & 300 & 369 & 0 & 300 & 2.76 & 50 & 4.65 & 3.75 & 759 & 1.00 & 1.13 & 0.98 & 1.05 & 1.38 \\
\hline $580-1$ & 300 & 369 & 0 & 300 & 2.76 & 81 & 4.65 & 0.00 & 262 & 1.00 & 1.37 & 0.99 & 0.93 & 1.55 \\
\hline $580-2$ & 300 & 369 & 0 & 300 & 2.76 & 81 & 4.65 & 1.89 & 668 & 1.00 & 1.49 & 1.31 & 1.28 & 1.76 \\
\hline $580-3$ & 300 & 369 & 0 & 300 & 2.76 & 81 & 4.65 & 2.42 & 723 & 1.00 & 1.39 & 1.22 & 1.23 & 1.65 \\
\hline $580-4$ & 300 & 369 & 0 & 300 & 2.76 & 81 & 4.65 & 2.78 & 784 & 1.00 & 1.38 & 1.21 & 1.24 & 1.64 \\
\hline $580-5$ & 300 & 369 & 0 & 300 & 2.76 & 81 & 4.65 & 3.17 & 838 & 1.00 & 1.35 & 1.19 & 1.23 & 1.61 \\
\hline \multicolumn{15}{|c|}{ Krefeld and Thurston [35] } \\
\hline $26-1$ & 254 & 456 & 0 & 254 & 8.03 & 40 & 2.22 & 0.54 & 207 & 1.00 & 1.03 & 0.84 & 1.11 & 1.11 \\
\hline $29 b-1$ & 254 & 456 & 0 & 254 & 8.03 & 38 & 2.22 & 0.37 & 160 & 1.00 & 0.91 & 0.74 & 0.99 & 0.97 \\
\hline $213.5-1$ & 254 & 456 & 0 & 254 & 8.03 & 39 & 2.22 & 0.24 & 148 & 1.00 & 0.93 & 0.74 & 0.99 & 0.98 \\
\hline $29 a-2$ & 254 & 456 & 0 & 254 & 8.03 & 37 & 2.22 & 0.43 & 217 & 1.00 & 1.19 & 0.97 & 1.29 & 1.28 \\
\hline
\end{tabular}




\begin{tabular}{|c|c|c|c|c|c|c|c|c|c|c|c|c|c|c|}
\hline Beam label & $\begin{array}{c}b_{w} \\
(\mathrm{~mm}) \\
\end{array}$ & $\begin{array}{c}d \\
(\mathrm{~mm})\end{array}$ & $\begin{array}{c}h_{f} \\
(\mathrm{~mm}) \\
\end{array}$ & $\begin{array}{c}b \\
(m m)\end{array}$ & $a / d$ & $\begin{array}{c}f_{c}^{\prime} \\
(M P a)\end{array}$ & $\begin{array}{l}\rho_{s l} \\
(\%)\end{array}$ & $\rho_{s t} \times f_{s t, y}$ & $V(k N)$ & $k_{f}$ & $\frac{V_{\text {exp. }}}{V_{N B B}}$ & $\frac{V_{\text {exp. }}}{V_{S B B B}}$ & $\frac{V_{\text {exp. }}}{V_{S M C F T}}$ & $\frac{V_{\text {exp. }}}{V_{A C I}}$ \\
\hline $29 b-2$ & 254 & 456 & 0 & 254 & 8.03 & 41 & 2.22 & 0.43 & 202 & 1.00 & 1.08 & 0.88 & 1.16 & 1.15 \\
\hline $29 c-2$ & 254 & 456 & 0 & 254 & 8.03 & 24 & 2.22 & 0.43 & 161 & 1.00 & 0.98 & 0.79 & 1.11 & 1.10 \\
\hline $29 d-2$ & 254 & 456 & 0 & 254 & 8.03 & 30 & 2.22 & 0.43 & 165 & 1.00 & 0.95 & 0.77 & 1.05 & 1.05 \\
\hline $29 e-2$ & 254 & 456 & 0 & 254 & 8.03 & 48 & 2.22 & 0.43 & 206 & 1.00 & 1.06 & 0.86 & 1.12 & 1.11 \\
\hline $29 g-2$ & 254 & 456 & 0 & 254 & 8.03 & 16 & 2.22 & 0.43 & 150 & 1.00 & 0.99 & 0.80 & 1.17 & 1.17 \\
\hline $213.5 a-2$ & 254 & 456 & 0 & 254 & 8.03 & 37 & 2.22 & 0.29 & 161 & 1.00 & 0.99 & 0.79 & 1.07 & 1.05 \\
\hline $218 a-2$ & 254 & 456 & 0 & 254 & 8.03 & 38 & 2.22 & 0.21 & 164 & 1.00 & 1.07 & 0.85 & 1.14 & 1.13 \\
\hline $29-3$ & 254 & 456 & 0 & 254 & 8.03 & 34 & 2.22 & 0.28 & 178 & 1.00 & 1.13 & 0.90 & 1.22 & 1.21 \\
\hline $318-1$ & 254 & 456 & 0 & 254 & 8.03 & 41 & 2.22 & 0.64 & 220 & 1.00 & 1.02 & 0.84 & 1.11 & 1.10 \\
\hline $321-1$ & 254 & 456 & 0 & 254 & 8.03 & 39 & 2.22 & 0.54 & 164 & 1.00 & 0.82 & 0.67 & 0.89 & 0.88 \\
\hline $318-2$ & 254 & 456 & 0 & 254 & 8.03 & 39 & 2.22 & 0.44 & 177 & 1.00 & 0.95 & 0.77 & 1.03 & 1.02 \\
\hline $321-2$ & 254 & 456 & 0 & 254 & 8.03 & 38 & 2.22 & 0.38 & 167 & 1.00 & 0.95 & 0.77 & 1.02 & 1.01 \\
\hline $313.5-3$ & 254 & 456 & 0 & 254 & 8.03 & 43 & 2.22 & 0.45 & 214 & 1.00 & 1.12 & 0.91 & 1.20 & 1.18 \\
\hline $318-3$ & 254 & 456 & 0 & 254 & 8.03 & 43 & 2.22 & 0.33 & 175 & 1.00 & 1.00 & 0.81 & 1.06 & 1.05 \\
\hline $321-3$ & 254 & 456 & 0 & 254 & 8.03 & 43 & 2.22 & 0.29 & 141 & 1.00 & 0.83 & 0.67 & 0.88 & 0.87 \\
\hline $4 A 3$ & 203 & 390 & 0 & 203 & 4.69 & 31 & 2.06 & 0 & 110 & 1.00 & 1.36 & 0.92 & 1.44 & 1.47 \\
\hline $11 A 2$ & 152 & 314 & 0 & 152 & 5.83 & 30 & 3.41 & 0 & 73 & 1.00 & 1.41 & 0.95 & 1.57 & 1.64 \\
\hline $12 A 2$ & 152 & 238 & 0 & 152 & 7.69 & 30 & 4.5 & 0 & 64 & 1.00 & 1.51 & 1.06 & 1.81 & 1.90 \\
\hline $18 A 2$ & 152 & 316 & 0 & 152 & 5.79 & 19 & 2.68 & 0 & 63 & 1.00 & 1.48 & 0.99 & 1.68 & 1.77 \\
\hline $18 B 2$ & 152 & 316 & 0 & 152 & 5.79 & 20 & 2.68 & 0 & 72 & 1.00 & 1.66 & 1.11 & 1.89 & 1.97 \\
\hline $18 C 2$ & 152 & 316 & 0 & 152 & 5.79 & 23 & 2.68 & 0 & 73 & 1.00 & 1.60 & 1.08 & 1.82 & 1.86 \\
\hline $18 D 2$ & 152 & 316 & 0 & 152 & 5.79 & 22 & 2.68 & 0 & 60 & 1.00 & 1.34 & 0.90 & 1.50 & 1.57 \\
\hline $13 A 2$ & 152 & 319 & 0 & 152 & 5.73 & 20 & 0.8 & 0 & 48 & 1.00 & 1.31 & 0.88 & 1.35 & 1.30 \\
\hline $14 A 2$ & 152 & 243 & 0 & 152 & 7.53 & 21 & 1.05 & 0 & 35 & 1.00 & 1.14 & 0.80 & 1.26 & 1.22 \\
\hline $15 A 2$ & 152 & 316 & 0 & 152 & 5.79 & 20 & 1.34 & 0 & 46 & 1.00 & 1.18 & 0.79 & 1.26 & 1.26 \\
\hline $15 B 2$ & 152 & 316 & 0 & 152 & 5.79 & 21 & 3.14 & 0 & 52 & 1.00 & 1.15 & 0.77 & 1.32 & 1.39 \\
\hline $16 A 2$ & 152 & 240 & 0 & 152 & 7.62 & 22 & 1.77 & 0 & 42 & 1.00 & 1.26 & 0.88 & 1.44 & 1.44 \\
\hline $17 A 2$ & 152 & 243 & 0 & 152 & 7.53 & 22 & 2.09 & 0 & 44 & 1.00 & 1.27 & 0.89 & 1.49 & 1.49 \\
\hline $18 E 2$ & 152 & 316 & 0 & 152 & 5.79 & 20 & 2.68 & 0 & 82 & 1.00 & 1.89 & 1.27 & 2.15 & 2.25 \\
\hline $19 A 2$ & 152 & 240 & 0 & 152 & 7.62 & 21 & 3.53 & 0 & 46 & 1.00 & 1.26 & 0.88 & 1.58 & 1.62 \\
\hline $20 A 2$ & 152 & 238 & 0 & 152 & 7.69 & 21 & 4.52 & 0 & 51 & 1.00 & 1.36 & 0.95 & 1.68 & 1.81 \\
\hline $21 A 2$ & 203 & 238 & 0 & 203 & 7.69 & 20 & 5.01 & 0 & 77 & 1.00 & 1.47 & 1.08 & 1.92 & 2.10 \\
\hline $2 A C$ & 152 & 254 & 0 & 152 & 9.6 & 23 & 1.32 & 0 & 38 & 1.00 & 1.12 & 0.78 & 1.23 & 1.21 \\
\hline $3 A C$ & 152 & 256 & 0 & 152 & 9.54 & 21 & 1.99 & 0 & 44 & 1.00 & 1.25 & 0.86 & 1.48 & 1.45 \\
\hline $4 A C$ & 152 & 254 & 0 & 152 & 9.6 & 16 & 2.63 & 0 & 38 & 1.00 & 1.14 & 0.79 & 1.40 & 1.45 \\
\hline $5 A C$ & 152 & 252 & 0 & 152 & 9.66 & 18 & 3.35 & 0 & 42 & 1.00 & 1.18 & 0.82 & 1.46 & 1.52 \\
\hline
\end{tabular}




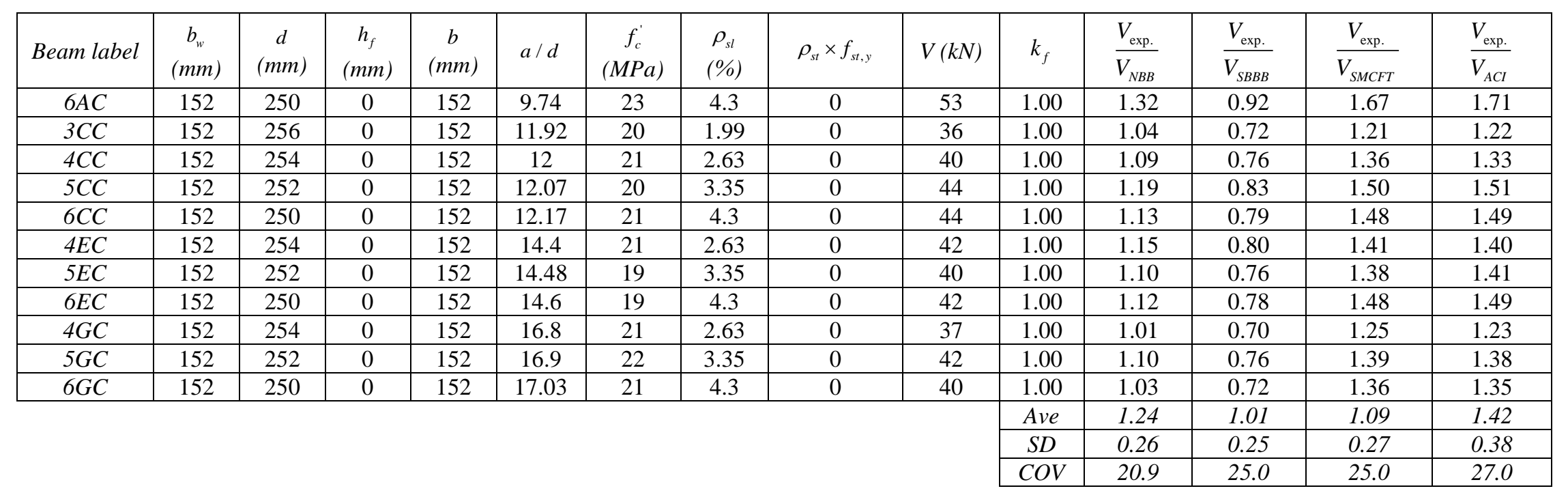


Table 3: Demerit points classification criteria

\begin{tabular}{|l|l|c|}
\hline$V_{\text {exp. }} / \mathrm{V}_{\text {ana. }}$ & Classification & Penalty \\
\hline$<0.5$ & Extremely Dangerous & 10 \\
\hline$[0.5-0.85[$ & Dangerous & 5 \\
\hline$[0.85-1.15[$ & Appropriate Safety & 0 \\
\hline$[1.15-2[$ & Conservative & 1 \\
\hline$\geq 2.0$ & Extremely Conservative & 2 \\
\hline
\end{tabular}


Table 4: Predictive performance of different approaches according to the modified version of the DPC on DB

\begin{tabular}{|c|c|c|c|c|c|c|c|c|}
\hline \multirow{2}{*}{$V_{\text {exp. }} / \mathrm{V}_{\text {ana. }}$} & \multicolumn{2}{|c|}{$N B B$ S } & \multicolumn{2}{c|}{ SBBB } & \multicolumn{2}{c|}{ SMCFT } & \multicolumn{2}{c|}{$A C I$} \\
\cline { 2 - 9 } & $\begin{array}{c}N^{o} \\
\text { samples }\end{array}$ & Total & $\begin{array}{c}N^{o} \\
\text { samples }\end{array}$ & Total & $\begin{array}{c}N^{o} \\
\text { samples }\end{array}$ & Total & $\begin{array}{c}N^{o} \\
\text { samples }\end{array}$ & Total \\
\hline$<0.5$ & 0 & 0 & 9 & 90 & 6 & 60 & 5 & 50 \\
\hline$[0.5-0.85[$ & 18 & 90 & 80 & 300 & 52 & 260 & 19 & 95 \\
\hline$[0.85-1.15[$ & 106 & 0 & 156 & 0 & 153 & 0 & 63 & 0 \\
\hline$[1.15-2[$ & 223 & 223 & 104 & 104 & 137 & 137 & 244 & 244 \\
\hline$\geq 2.0$ & 2 & 4 & 0 & 0 & 1 & 2 & 18 & 36 \\
\hline$\sum P E N$ & 349 & 317 & 349 & 494 & 349 & 459 & 349 & 425 \\
\hline
\end{tabular}


Table 5: Predictive performance of different approaches according to the modified version of the DPC on RDB

\begin{tabular}{|c|c|c|c|c|c|c|c|c|}
\hline \multirow{2}{*}{$V_{\text {exp. }} / \mathrm{V}_{\text {ana. }}$} & \multicolumn{2}{|c|}{$N B B$} & \multicolumn{2}{c|}{$S B B B$} & \multicolumn{2}{c|}{ SMCFT } & \multicolumn{2}{c|}{ ACI } \\
\cline { 2 - 9 } & $\begin{array}{c}N^{o} \\
\text { samples }\end{array}$ & Total & $\begin{array}{c}N^{o} \\
\text { samples }\end{array}$ & Total & $\begin{array}{c}N^{o} \\
\text { samples }\end{array}$ & Total & $\begin{array}{c}N^{o} \\
\text { samples }\end{array}$ & Total \\
\hline$<0.5$ & 0 & 0 & 0 & 0 & 0 & 0 & 0 & 0 \\
\hline$[0.5-0.85[$ & 4 & 20 & 62 & 310 & 44 & 220 & 10 & 50 \\
\hline$[0.85-1.15[$ & 95 & 0 & 141 & 0 & 136 & 0 & 61 & 0 \\
\hline$[1.15-2[$ & 199 & 199 & 97 & 97 & 119 & 119 & 214 & 214 \\
\hline$\geq 2.0$ & 2 & 4 & 0 & 0 & 1 & 2 & 15 & 30 \\
\hline$\sum P E N$ & 300 & 223 & 300 & 407 & 300 & 341 & 300 & 294 \\
\hline
\end{tabular}




\section{Figure Caption List}

Figure 1: Sensitivity analysis for: a) SMCFT model; b) the tensile stress in the cracked concrete $(\beta)$; and the inclination of the diagonal compressive stress in the web of the section $(\theta)$

Figure 2: The relation between $\beta_{N B B}$ vs. $\frac{\bar{\sigma}_{s t}}{f_{c}^{\prime}}$ and $\frac{\rho_{s l} \times E_{s l}}{f_{c}^{\prime}} \times\left(\frac{b_{w}}{d}\right)$

Figure 3: Relation between $\theta_{N B B}$ and $\beta_{N B B}$

Figure 4: Area of T-cross section beam considered in: a) RILEM TC162-TDF [14] recommendations (equation (15)), b) equation (16)

Figure 5: Effects of flange on the load carrying capacity according to Thamrin et al. [13] and RILEM TC162-TDF [14] recommendation.

Figure 6: Distribution of the variables used in data base (DB)

Figure 7: Values of the experimental $v s$. analytical ratio for the T-cross section beams of the data base ( $\left.x+y=\frac{\bar{\sigma}_{s t}}{f_{c}^{\prime}}+\frac{200000 \times \rho_{s l}}{f_{c}^{\prime}} \times\left(\frac{b_{w}}{d}\right)\right)$

Figure 8: Values of the experimental $v s$. analytical ratio for the analyzed approaches, considering the results from the collected data base $\left(x+y=\frac{\bar{\sigma}_{s t}}{f_{c}^{\prime}}+\frac{200000 \times \rho_{s l}}{f_{c}^{\prime}} \times\left(\frac{b_{w}}{d}\right)\right)$

Figure 9: Distribution of the results for different models.

Figure 10: Values of the experimental vs. analytical ratio, considering the results from the RDB

Figure 11: The ratio between the predicted and experimental shear strength values with respect to the $f_{c}^{\prime}, d, \rho_{s l}$, $\bar{\sigma}_{s t}, b_{w}$, and $A_{f} / A_{t}$ 


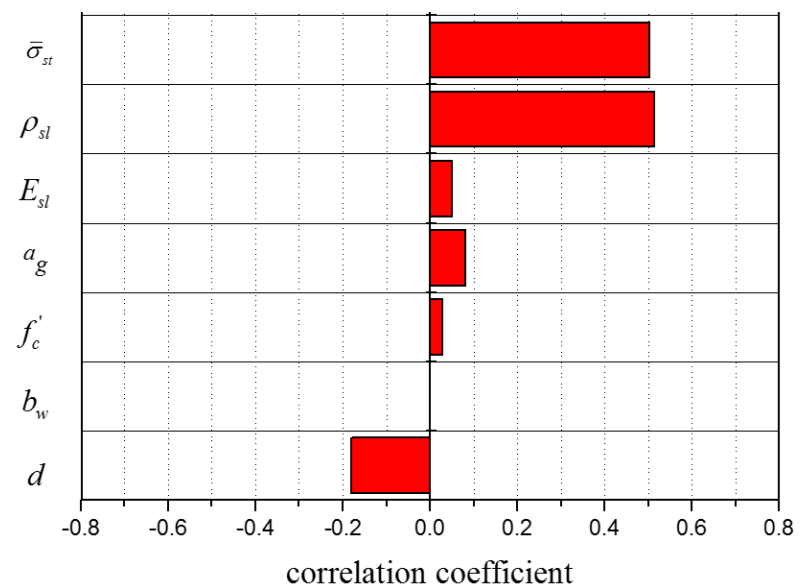

a)

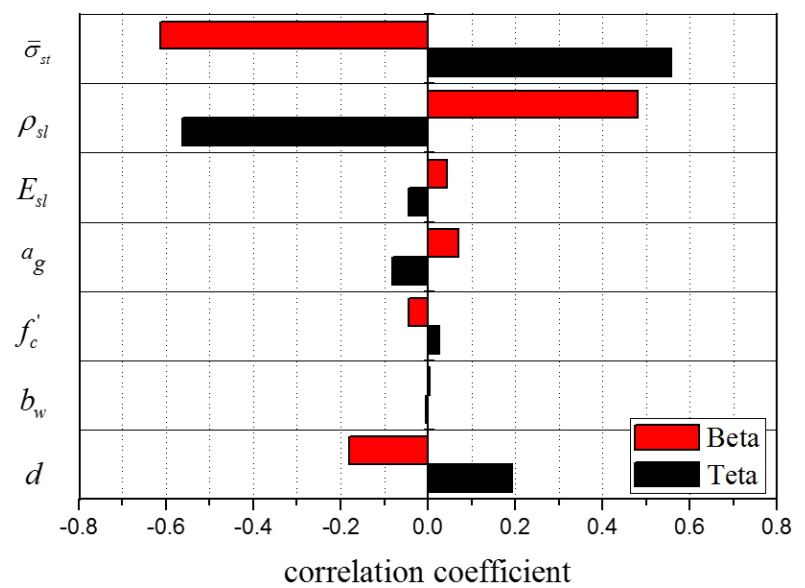

b)

Figure 1: Sensitivity analysis for: a) SMCFT model; b) the tensile stress in the cracked concrete ( $\beta$ ); and the inclination of the diagonal compressive stress in the web of the section $(\theta)$ 


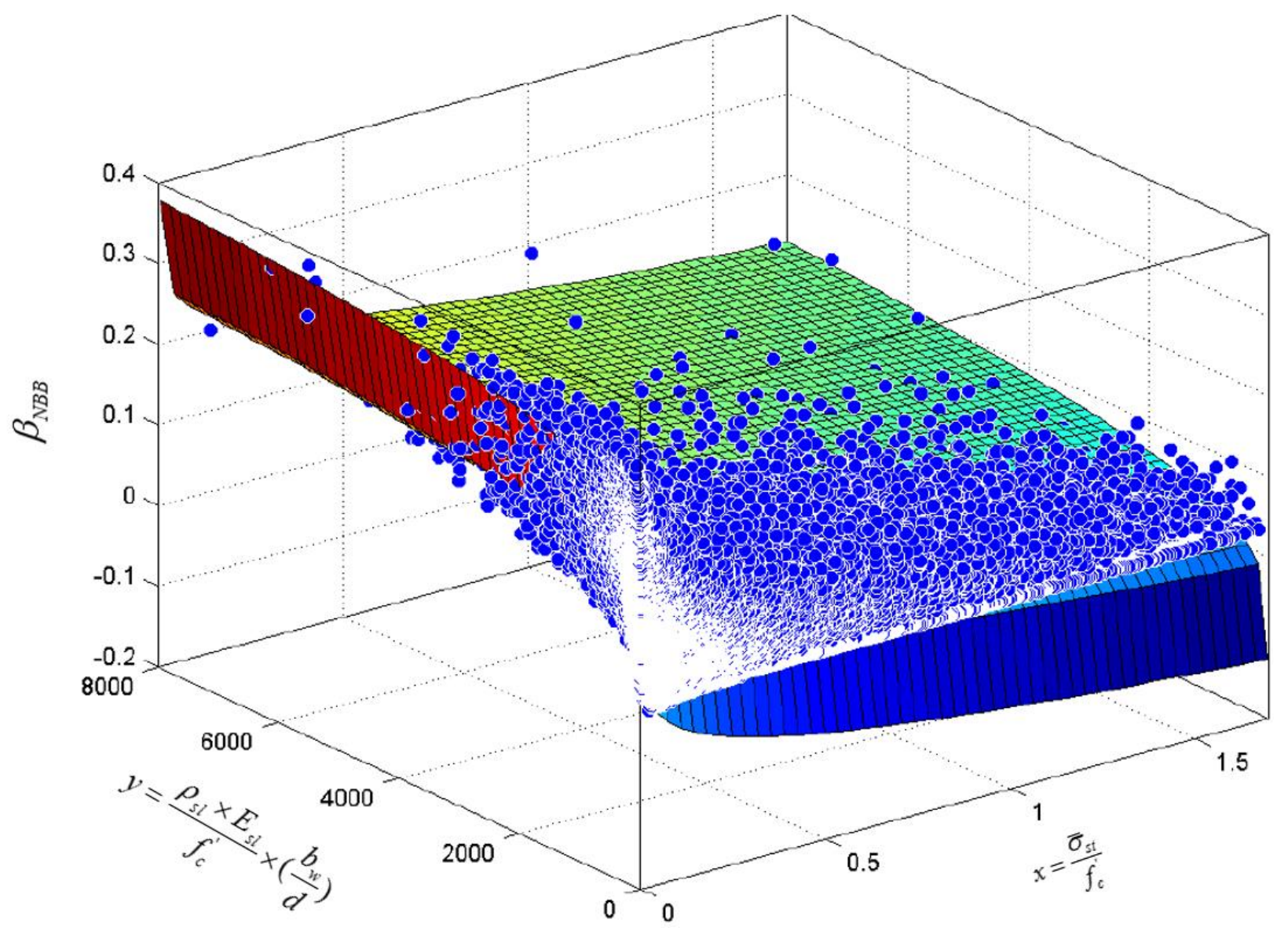

Figure 2: The relation between $\beta_{N B B}$ vs. $\frac{\bar{\sigma}_{s t}}{f_{c}^{\prime}}$ and $\frac{\rho_{s l} \times E_{s l}}{f_{c}^{\prime}} \times\left(\frac{b_{w}}{d}\right)$ 


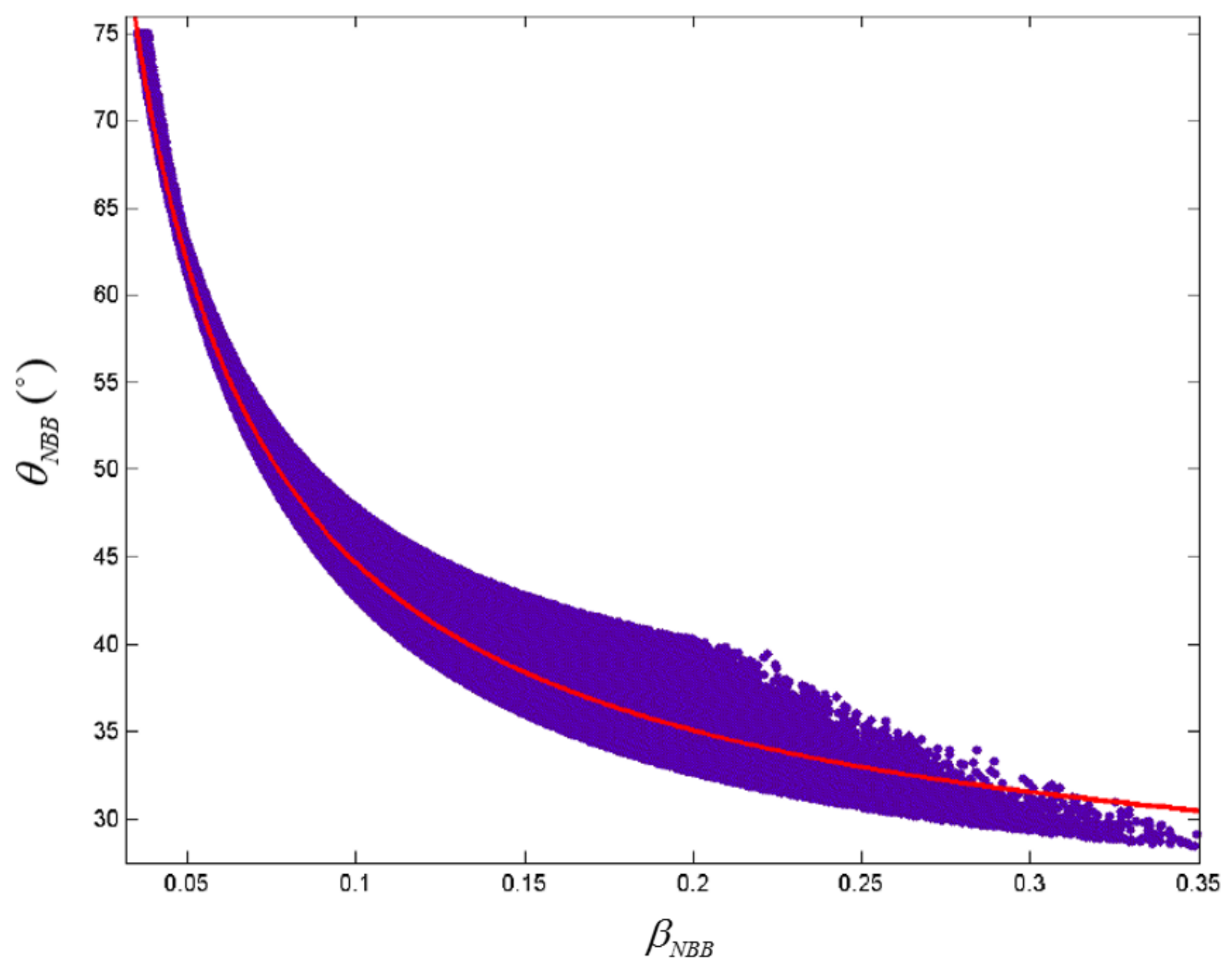

Figure 3: Relation between $\theta_{N B B}$ and $\beta_{N B B}$ 


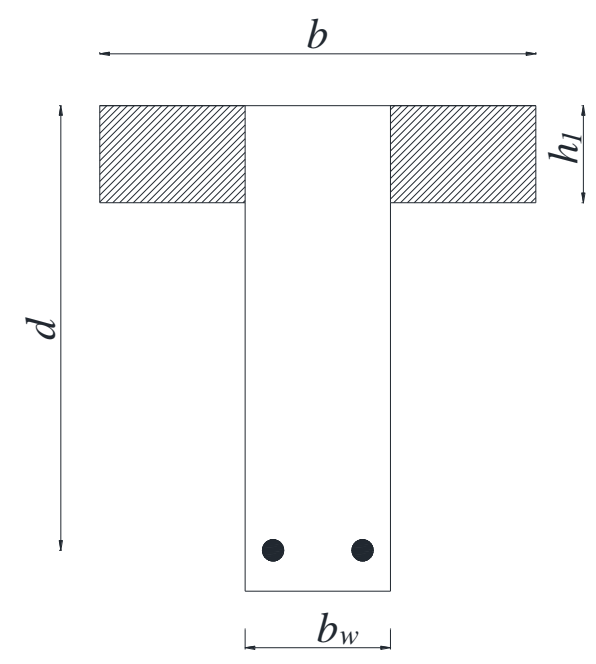

a)

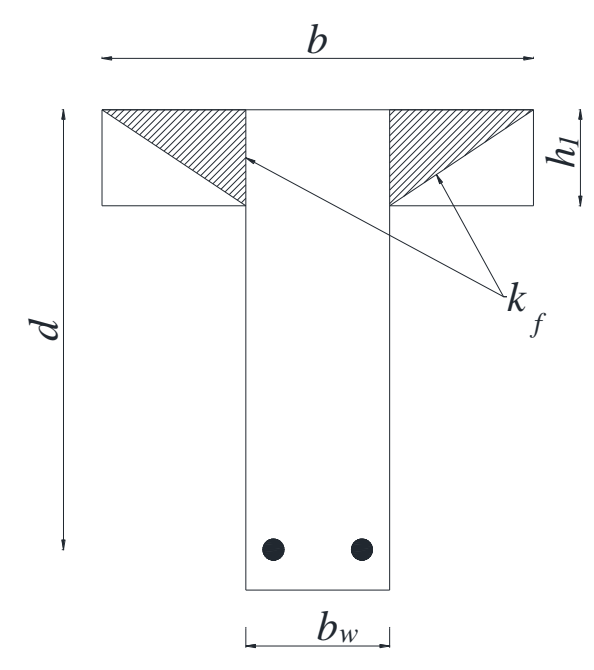

b)

Figure 4: Area of T-cross section beam considered in: a) RILEM TC162-TDF [14] recommendations (equation (15)), b) equation (16) 


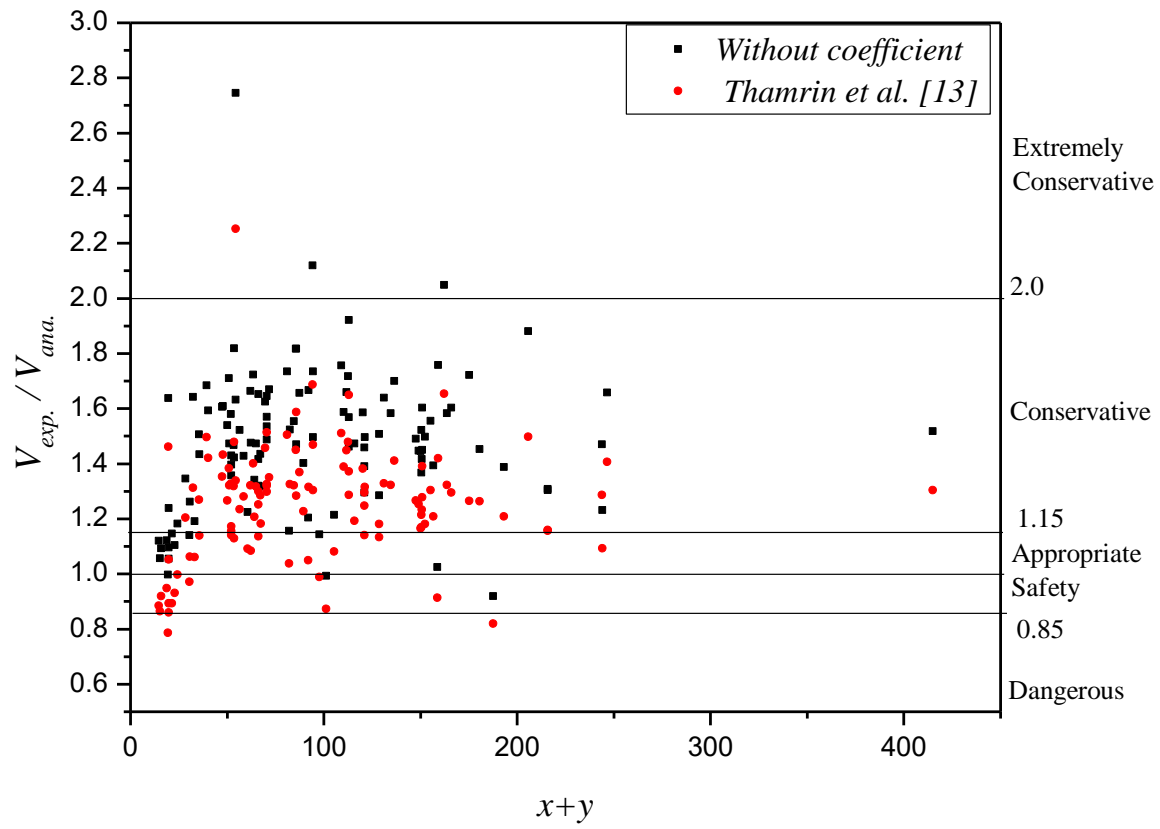

a) Thamrin et al. [13] suggestion

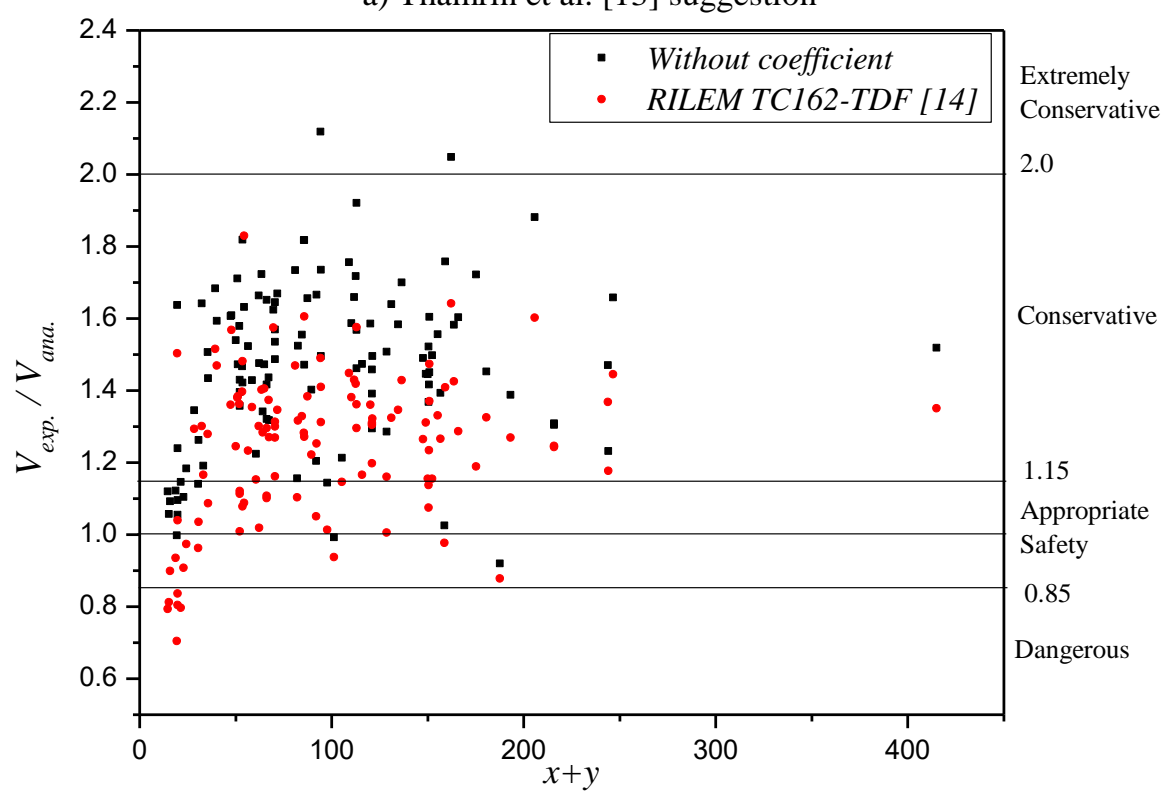

b) Rilem TC162-TDF [14] suggestion

Figure 5: Effects of flange on the load carrying capacity according to Thamrin et al. [13] and RILEM TC162-TDF [14] recommendation. 

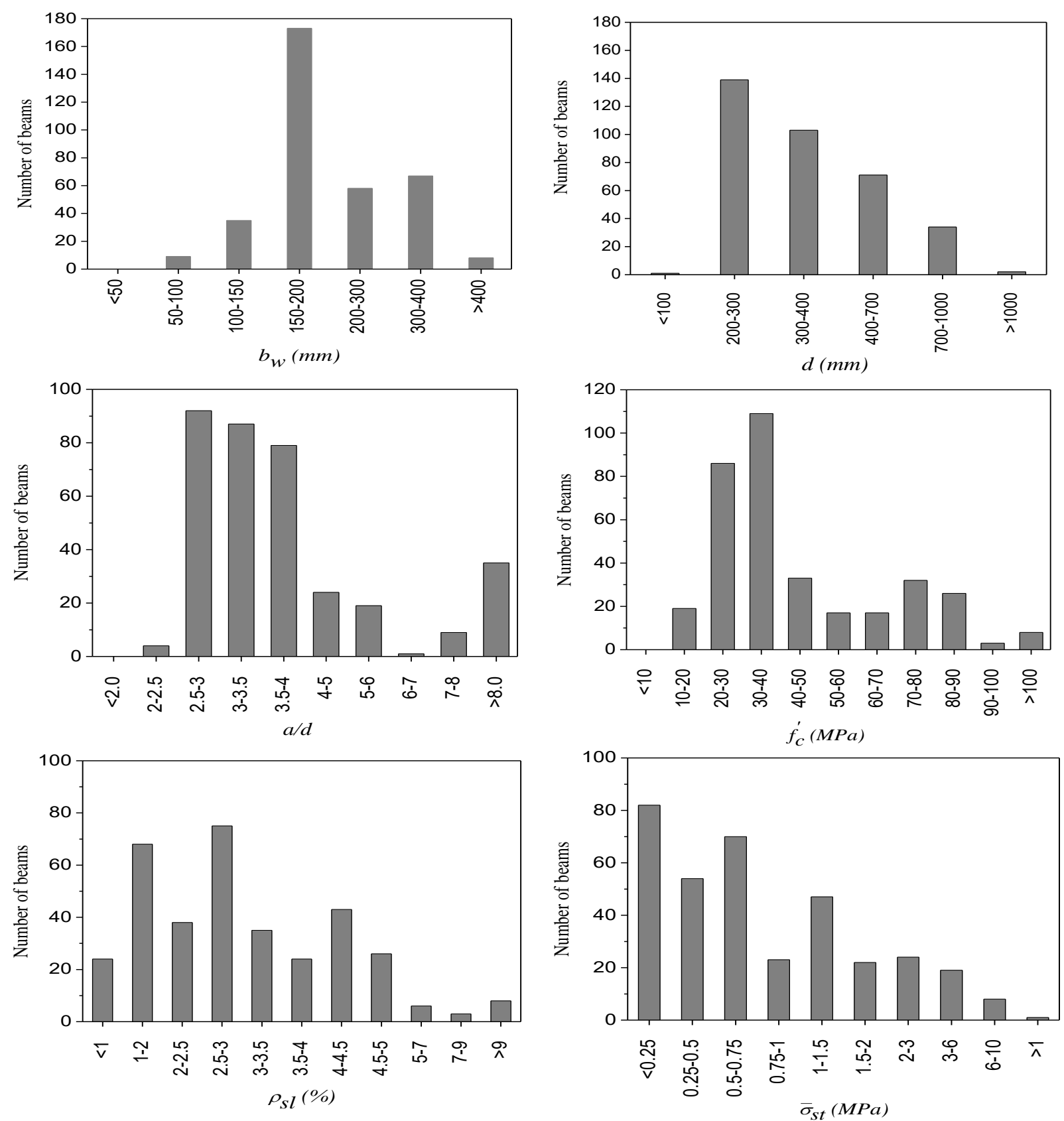

Figure 6: Distribution of the variables used in data base (DB) 


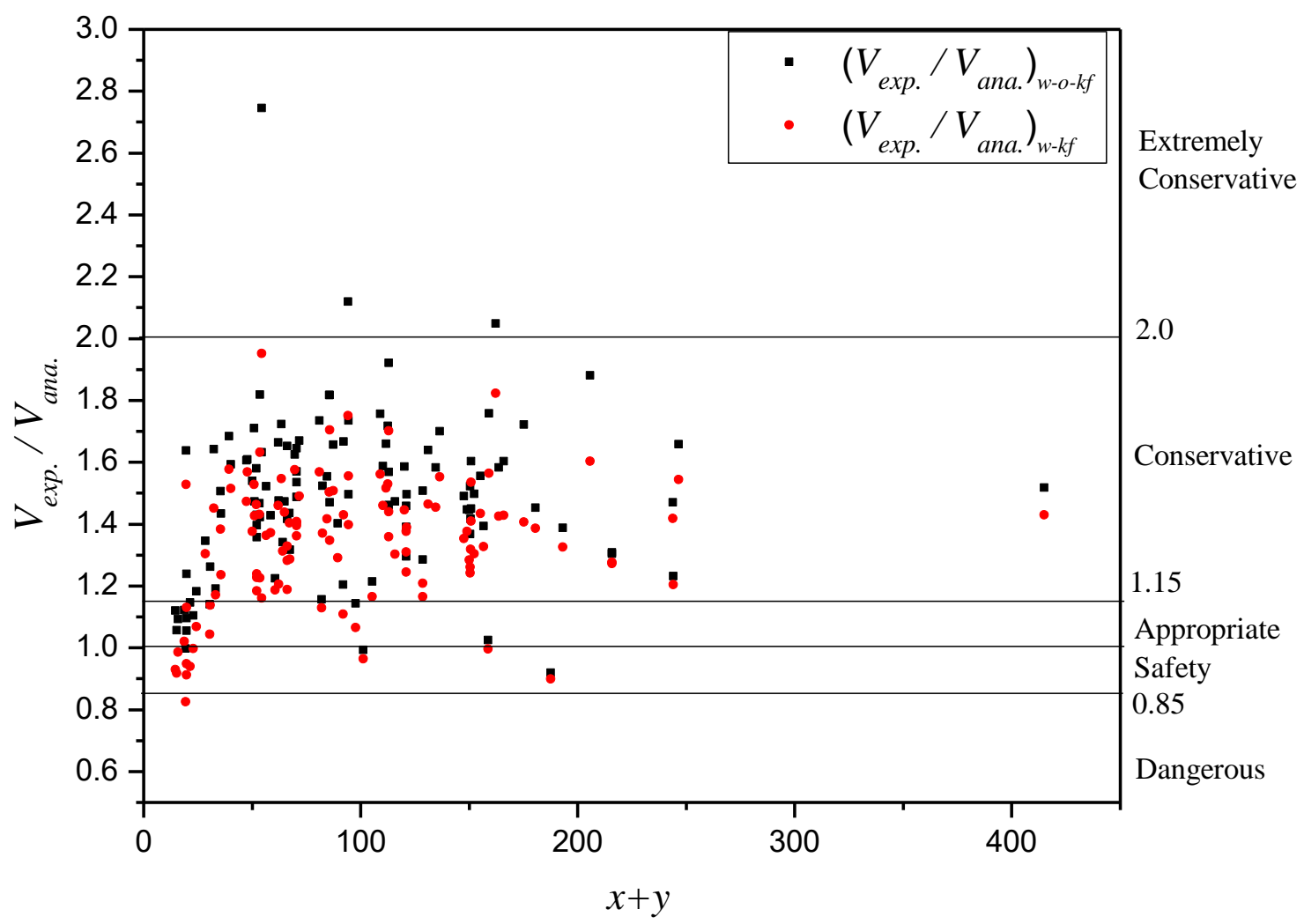

Figure 7: Values of the experimental $v s$. analytical ratio for the T-cross section beams of the data base (

$$
\left.x+y=\frac{\bar{\sigma}_{s t}}{f_{c}^{\prime}}+\frac{200000 \times \rho_{s l}}{f_{c}^{\prime}} \times\left(\frac{b_{w}}{d}\right)\right)
$$




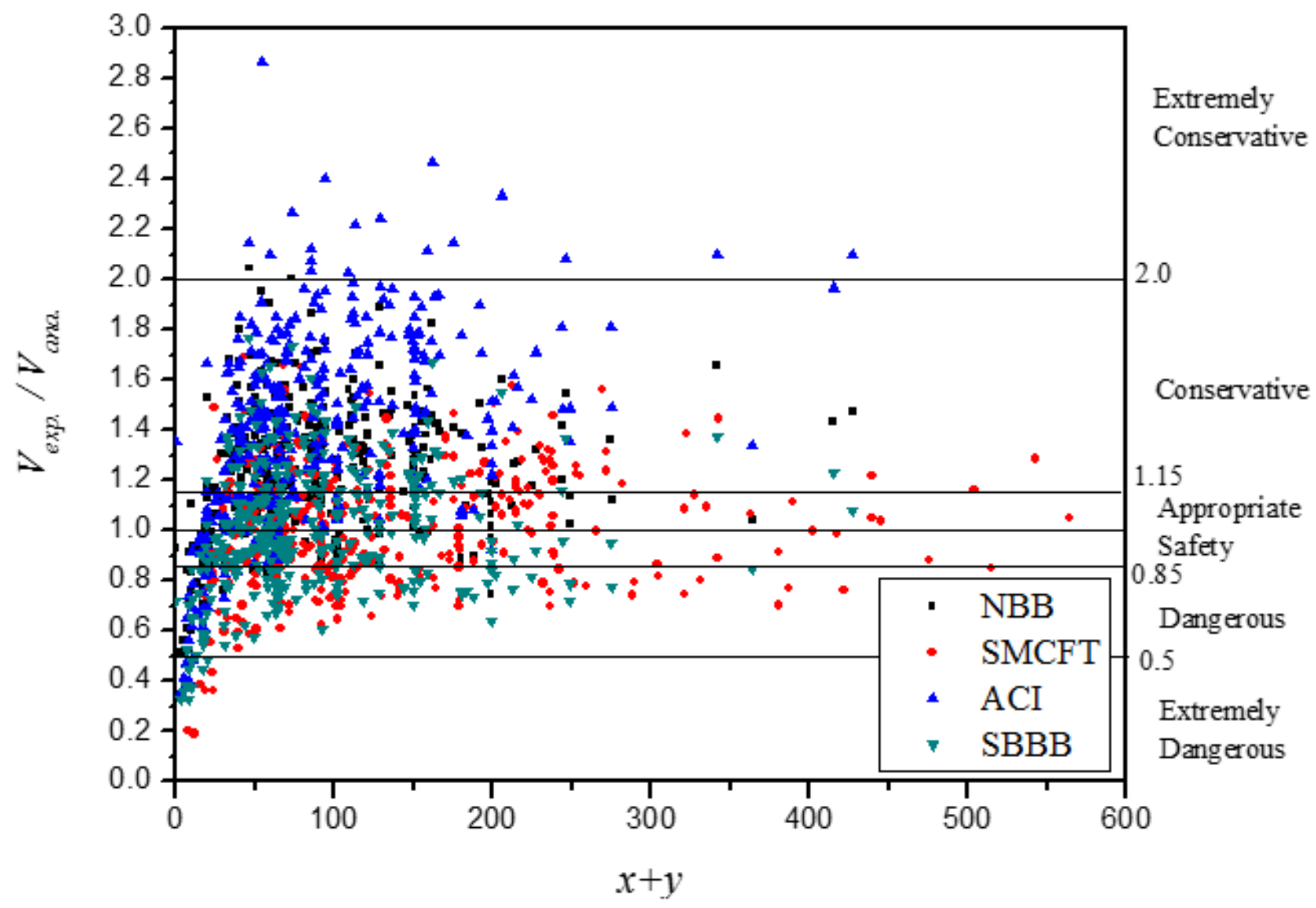

Figure 8: Values of the experimental $v s$. analytical ratio for the analyzed approaches, considering the results from the collected data base $\left(x+y=\frac{\bar{\sigma}_{s t}}{f_{c}^{\prime}}+\frac{200000 \times \rho_{s l}}{f_{c}^{\prime}} \times\left(\frac{b_{w}}{d}\right)\right)$ 

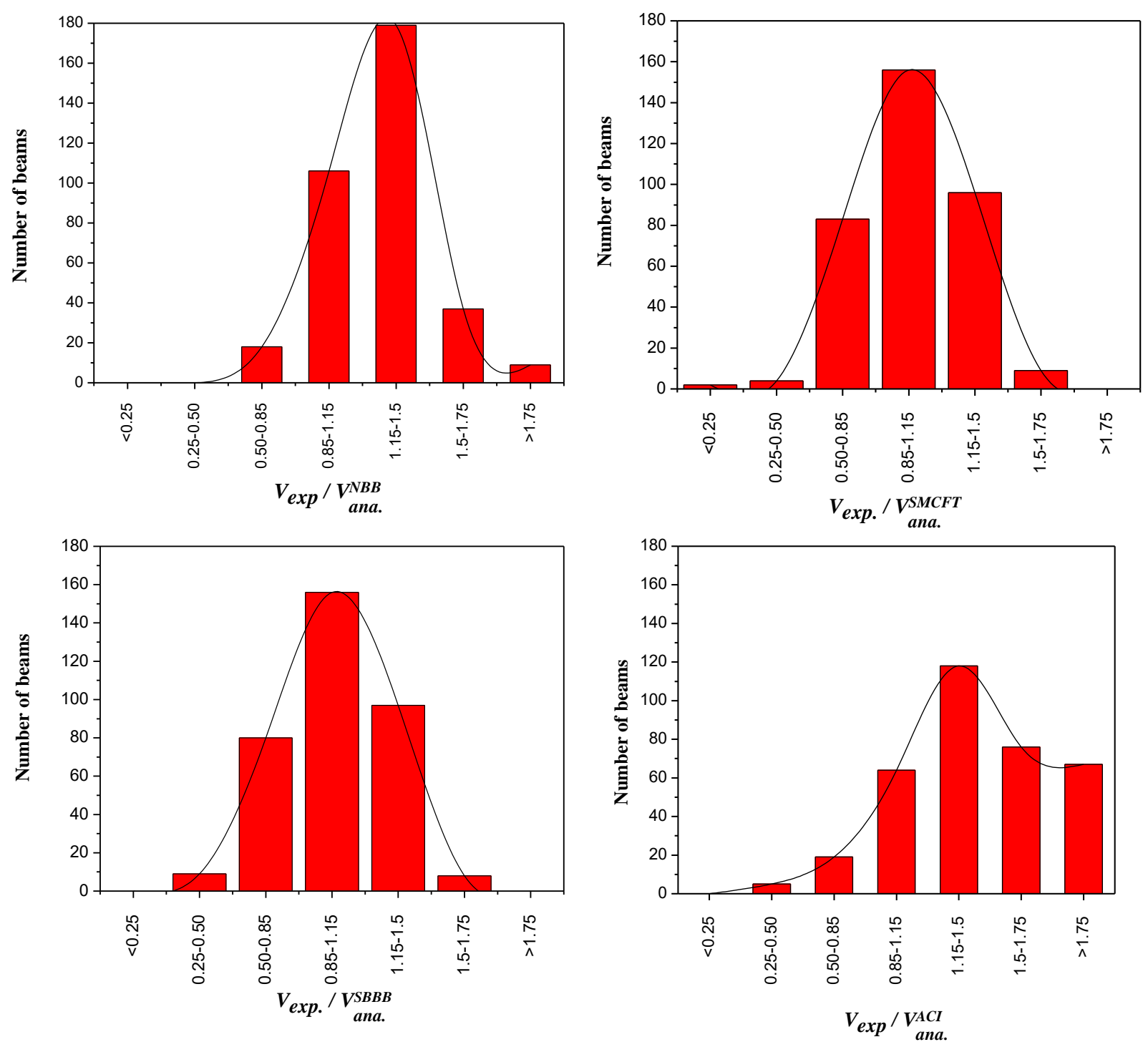

Figure 9: Distribution of the results for different models. 


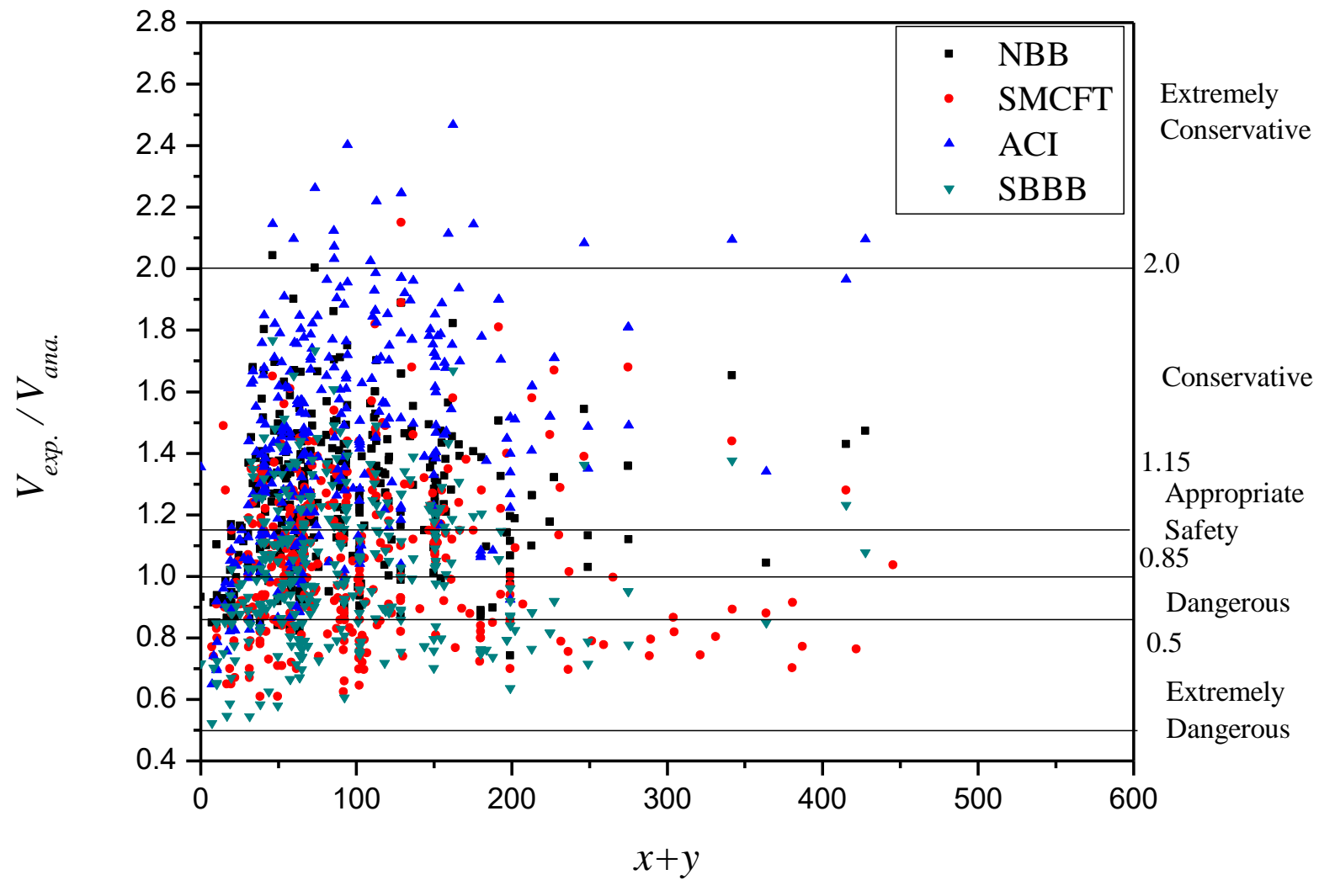

Figure 10: Values of the experimental $v s$. analytical ratio, considering the results from the RDB 

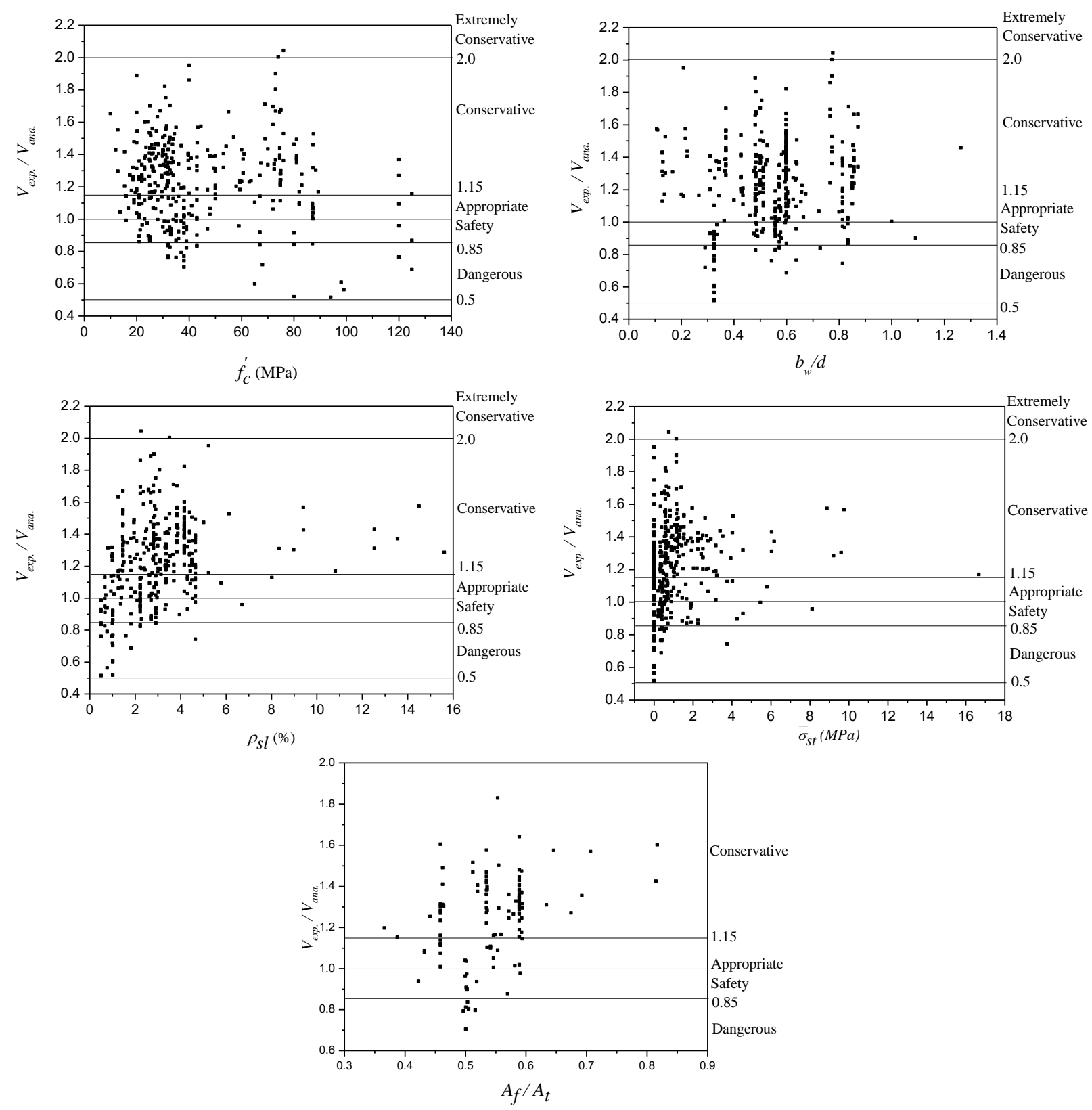

Figure 11: The ratio between the predicted and experimental shear strength values with respect to the $f_{c}^{\prime}, d, \rho_{s l}$,

$$
\bar{\sigma}_{s t}, b_{w} \text {, and } A_{f} / A_{t}
$$

